\title{
Bubbles, Crashes and the Financial Cycle: Insights from a Stock-Flow Consistent Agent-Based Macroeconomic Model
}

Sander van der Hoog Herbert Dawid 


\title{
Bubbles, Crashes and the Financial Cycle: Insights from a Stock-Flow Consistent Agent-Based Macroeconomic Model ${ }^{\star}$
}

\author{
Sander van der $\operatorname{Hoog}^{a}$ and Herbert Dawid ${ }^{b}$
}

This version: May 18, 2015

\begin{abstract}
This paper explores how different credit market- and banking regulations affect business fluctuations. Capital adequacy- and reserve requirements are analysed for their effect on the risk of severe downturns. We develop an agent-based macroeconomic model in which financial contagion is transmitted through balance sheets in an endogenous firm-bank network, that incorporates firm bankruptcy and heterogeneity among banks to capture the fact that contagion effects are bank-specific. Using concepts from the empirical literature to identify amplitude and duration of recessions and expansions we show that more stringent liquidity regulations are best to dampen output fluctuations and prevent severe downturns. Under such regulations both leverage along expansions and amplitude of recessions become smaller. More stringent capital requirements induce larger output fluctuations and lead to deeper, more fragile recessions. This indicates that the capital adequacy requirement is pro-cyclical and therefore not advisable as a measure to prevent financial contagion.
\end{abstract}

Key words: Financial Crises, Credit market and banking regulations, Financial Fragility, Agent-Based Macroeconomics.

JEL Classification: C63, E03, G01, G28

${ }^{\star}$ This paper has benefitted greatly from comments and suggestions by the participants of the CEF Conference 2013 in Vancouver, the CeNDEF@15 Symposium in Amsterdam, the 1st Workshop on Agent-based Macroeconomics in Bordeaux, the CEF Conference 2014 in Oslo, the Post-Keynesian Economics Conference in Kansas City 2014, and the Conference of the Eastern Economics Association in New York City 2015. We are also grateful for comments by the members of the Financial Stability Department of the Bank of Canada. We thank Simon Gemkow and Philipp Harting for co-developing and programming parts of the model. The graphic design for the illustration of the model was done by Britta Stodieck, 2014. SH acknowledges Universität zu Köln, for use of their high-performance computing services on the CHEOPS cluster.

${ }^{a}$ Chair for Economic Theory and Computational Economics (ETACE), Dept. of Business Administration and Economics, Bielefeld University, Germany. Phone: +49 521106 5638, Fax: +49 521106 89005, E-mail: svdhoog@wiwi.uni-bielefeld.de.

${ }^{b}$ Chair for Economic Theory and Computational Economics (ETACE), Dept. of Business Administration and Economics and Center for Mathematical Economics, Bielefeld University, Germany. E-mail: hdawid@wiwi.unibielefeld.de 


\section{Contents}

1 Introduction 3

2 Related literature $\quad 6$

3 The Model $\quad 9$

3.1 Overall Structure . . . . . . . . . . . . . . . . . . . . . . . 9 9

3.2 Firm sequence of activities . . . . . . . . . . . . . . . . . . 10

3.3 Consumption goods sector . . . . . . . . . . . . . . . . 11

3.4 Investment goods sector . . . . . . . . . . . . . . . . . . . 11

3.5 Labour market . . . . . . . . . . . . . . . . . . . . . . 12

3.6 Financial management . . . . . . . . . . . . . . . . . . . . . . . 12

3.7 Dividend payout policy $\ldots \ldots \ldots \ldots \ldots \ldots \ldots$

3.8 Firm credit demand . . . . . . . . . . . . . . . . . . . . . 13

3.9 Firm bankruptcy: Entry and Exit . . . . . . . . . . . . . . . . 14

3.10 Debt deleveraging and restructuring . . . . . . . . . . . . . . . 14

3.11 Banking sector . . . . . . . . . . . . . . . . . . . . 15

3.11 .1 Bank balance sheet . . . . . . . . . . . . . . . . . . 15

3.11 .2 Bank accounting . . . . . . . . . . . . . . . . 16

3.11.3 Bank credit supply and risk-taking behaviour . . . . . . . . . . . . . 17

3.11 .4 Probability of Default . . . . . . . . . . . . . . . . . 17

3.11.5 The updating frequency of the Probability of Default . . . . . . . . . . 17

3.11 .6 Credit risk . . . . . . . . . . . . . . . . . . . . . . . . 18

3.11 .7 Interest rate rule . . . . . . . . . . . . . . . . . . . . . . . . 18

3.11 .8 Capital Adequacy Requirement . . . . . . . . . . . . . . . . . . . . . . . 18

3.11 .9 Reserve Requirement . . . . . . . . . . . . . . . . . . . . . . 19

3.12 Rationing effects . . . . . . . . . . . . . . . . . . . . . 19

4 Results $\quad 20$

4.1 Methodology and Experimental Design . . . . . . . . . . . . . . . . 20

4.2 Parametrization and empirical calibration . . . . . . . . . . . . . 20

4.3 Baseline Scenario . . . . . . . . . . . . . . . . . . . . . 22

4.3.1 Prevention and mitigation policies ................. 24

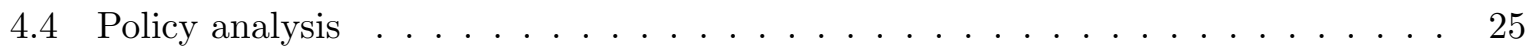

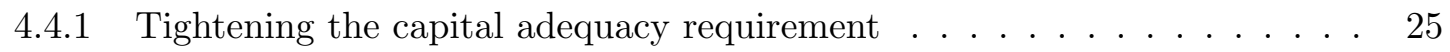

4.4 .2 Tightening the reserve requirement . . . . . . . . . . . . . . . . . 29

5 Discussion $\quad 30$

A Note on behavioral assumptions and model consistency 41

B Appendix: Recession Analysis $\quad 44$

B.1 Terminology and Definitions . . . . . . . . . . . . . . . . . . 44

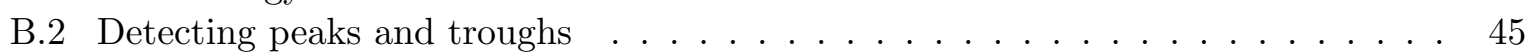

B.3 Statistical properties of business and financial cycles . . . . . . . . . . 45 


\section{Introduction}

The agenda of this paper is to improve our understanding of the mechanisms responsible for business fluctuations and to explore how the amplitude of such fluctuations is affected by different types of banking- and credit market regulations. It is well documented that business fluctuations are associated to substantial welfare costs (see e.g. Gali et al., 2007) and these costs are particularly severe for deep recessions. Such severe downturns are typically associated with massive job losses and firm bankruptcies, which induce a substantial reduction in physical and human capital, thereby negatively affecting not only current output but also growth perspectives (see e.g. Verho (2008) or Berkmen et al. (2009) for treatments of the potentially negative long-term effects of recessions). As many historical examples show, severe recessions also induce an increased danger of political instability and the erosion of trust in valuable economic institutions, as witnessed for example by the bank runs and subsequent banking panic during the Great Depression. But also more recently, the anti-austerity demonstrations across Europe are showing a growing political divide.

Hence, avoiding deep recessions is a particularly urgent goal for economic policy makers, apart from the overall objective of smoothing the business cycle. Whereas a large body of literature addresses the issue of business cycle smoothing, only a small part of this work explicitly addresses the impact of different policy measures on the lower part of the distribution of downturns, i.e. on the severity of the strongest downturns that might occur under different policy scenarios.

This paper focuses exactly on this aspect of business cycle fluctuations and explores to what extent more stringent regulations are suitable tools to avoid severe downturns in an economy. The analysis is carried out in the context of an agent-based macroeconomic model with a strong focus on the firm's financial management and the banking sector. The main part of the model is a credit market embedded in a full-fledged macroeconomic setting with a fully functioning production sector for consumption goods, a labour market, and a market for investment goods (see Fig.1 for an illustration of the model). In the analysis we include feedback effects from the real sector to the banking sector that might attenuate or exacerbate the pro-cyclicality of the credit and banking regulation. The real sector endogenously generates expansions and recessions, which allows to test whether in scenarios with more restrictive capital- or reserve requirements we obtain statistically significant differences in the amplitude and duration of recessions.

In the aftermath of the recent 2007-09 financial and economic crisis a large body of literature has emerged which aims to capture the feedback effects between financial and real cycles. We contribute to this literature by developing and exploiting a model which endogenously generates cycles in the spirit of Minsky's Financial Instability Hypothesis (see Minsky, 1978, 1986) and captures the main properties of leverage cycles, as described e.g. in Geanakoplos (2009).

The framework is based on a taxonomy of firms into financially sound (healthy) firms versus financially unsound (unhealthy) firms. This dichotomy is based on the Minskyan notion that a firm may be in a financial position that is characterized as hedge finance, speculative finance, or Ponzi finance. This classifies firms according to their financial fragility and is therefore directly related to their risk of insolvency. The persistent financial heterogeneity of both banks and firms are the outcome of a dynamic process involving two financial contagion mechanisms, a balance sheet mechanism and a bank lending mechanism.

The balance sheet mechanism works through the balance sheet of the firm. The firm's financial robustness determines its default risk and its credit worthiness. 'Good' healthy firms are able to secure credit if the bank has sufficient amounts of liquidity available, whereas 'bad' unhealthy firms are likely to be credit rationed. If the 'bad' firms default on their loans this 
affects the balance sheets of the banks through a write-off of bad debt on a fraction of the loans. If this happens, the bank's equity declines and so does its willingness to lend to other firms. The contagion effect consists in the effect that all other firms, sound or unsound, now find it more difficult to secure a loan.

The bank lending mechanism depends on the excess liquidity available to the bank. Since liquidity is endogenously determined by deposits and withdrawals by firms and households, the bank will restrict lending when it approaches the minimum reserve ratio (a policy parameter). The contagion effect results from the fact that if a firm with a large liquidity demand has obtained a loan this will restrict the bank's available liquidity and limit the credit supply to all other firms. Regardless of whether the other firms are healthy or risky, they are now more likely to be credit rationed.

Credit market and banking regulations are affecting the magnitude of the two contagion mechanisms. First, changing the minimum Reserve Requirement Ratio (RRR) affects the bank lending mechanism. ${ }^{1}$ A more restrictive reserve ratio makes banks less willing to lend and therefore credit rationing becomes more likely.

Second, the Capital Adequacy Requirement (CAR, or minimum base capital requirement) affects the balance sheet mechanism. A weak capital regulation allows banks to increase their risk exposure and therefore strengthens the financial contagion effect. The contagion does not only apply to firms but also to banks. A higher credit supply to 'bad' firms implies that if they default the bad debt will be higher resulting in other banks to bear the brunt of having to write off bad debts as well.

The question how macroeconomic outcomes are affected by these credit regulations evolves around the well-known trade-off between output growth and aggregate volatility. Loose, nonrestrictive regulations tend to lead to higher leverage ratios of both firms and banks. As a consequence, this results in higher growth rates but also leads to more volatility.

On the other hand, more stringent capital requirements restrict banks' risk-taking behaviour, resulting in the most risky firms to be credit rationed. A very lax capital requirement allows even the most highly leveraged firms to obtain loans, but now the bank's liquidity reserve requirement could become binding. If the liquidity constraint is tight, this constraint will ensure financial stability. However, it might also lead to reduced economic growth as the riskier firms now find themselves cut off from liquidity. Hence, there exists a trade-off between growth and stability.

Furthermore, if both constraints are non-restrictive or lax, the banking sector is allowed to provide a lot of liquidity to the real sector, leading to over-investments in production capacity that are characteristic of a financially fragile boom phase (see, e.g., Delli Gatti and Gallegati, 1992). This excess production capacity temporarily leads to higher output levels, but on the long run can turn out to be detrimental to financial stability. It should therefore be anticipated that if requirements on reserves and core capital are weak, the risk for severe downturns is particularly large.

Another effect of the non-restrictive, lax liquidity requirements is that this encourages overleveraging by the banks, the supply of new loans is high, and the bank takes on more risk. They continue to supply new credit to large firms in order to roll-over their debts, crowding out the credit requests of smaller firms that may become illiquid as a result. These illiquidities of healthy firms signals an inefficient allocation of credit resulting from a "congestion" effect on the credit market. Instead, in a scenario with a more restrictive reserve requirement the unhealthy firms with large credit requests are credit rationed much sooner and become insolvent, while the smaller healthier firms obtain the liquidity they need to produce. The insolvencies indicate that banks are letting the unsound firms exit the market instead of supporting them and crowding out the smaller, healthier firms. 
Summarizing, it seems that a prudent regulatory policy should strike a balance between allowing banks to provide a sufficient amount of liquidity to any firm that needs it for productive purposes (the safe, healthy, and financially sound firms), while at the same time it should prevent banks from re-financing the debts of firms that already have a very high leverage ratio.

A main insight from our analysis is that a tightening of the credit and banking regulations has effects on the most severe downturns (the lower part of the distribution of recession amplitudes), but these effects differ qualitatively between the capital adequacy and the reserve requirement, resp. In particular, strengthening the capital requirement leads to an increase in the amplitude of the worst downturns, whereas more stringent liquidity constraints induce a reduction of the amplitude of recessions in the lower part of the distribution. Furthermore, these effects appear in a range of regulatory parameters where the median amplitude of recessions is not significantly affected by either of the two variations of the regulatory scheme. Hence, this result is different from a blanket stabilization policy that focusses on smoothing the business cycle, and specifically affects the most severe recessions.

The agent-based approach employed in our analysis allows us to identify in detail the microlevel mechanisms that are responsible for these different implications of the two considered regulatory schemes. Based on this analysis, we will obtain a clear intuition about their potential effects on the economic fluctuations and the risks for severe downturns.

The insights obtained by our analysis have clear policy implications since the considered regulatory schemes are at the core of the Basel II/III framework. An argument against the Basel II capital requirements is that they are pro-cyclical. During a downturn the probability of default and hence the probability of loan losses increases. This leads to higher demand for collateral and reduces the available capital buffers of banks. The reduction of the capital buffers limits the banks' capacity to lend in the future and reduces the overall supply of credit, thereby reducing investments and further exacerbating the downturn. These mechanisms are at the centre of theories of financial instability, such as the Leverage Cycle (Geanakoplos, 2009) and the Financial Instability Hypothesis (Minsky, 1978). Our results shed light on the question as to how relevant such mechanisms are in a macroeconomic setting and provide some guidance how additional regulatory measures might dampen or even amplify such an effect.

The remainder of the paper is organized as follows. In the next section we discuss different streams of relevant literature. The model is presented in Section 3 and in Section 4 we summarize the main results concerning the effects of two scenarios, namely a tighter capital adequacy requirement and a tighter reserve requirement. The scenarios illustrate the various mechanisms we described above in the introduction, for a multitude of parametrizations of the model. The results of these two scenarios are then compared to the results of a baseline scenario. Finally, in Section 5 we conclude and offer some suggestions for further research.

Policy response to the 2007-8 financial crisis in the U.S. and in Europe

The policy response by the U.S. Government and the FED to the Global Financial Crisis consisted of a mixture of fiscal and monetary policy measures. It included a bank rescue package (the Troubled Asset Relief Program (TARP) in 2008), a fiscal stimulus package, and the FED initiated Quantitative Easing starting from November 2008.

There are mixed reports on the success of the Quantitative Easing policy and its monetary policy effectiveness. The assessments about the impact of the Federal Reserve's large-scale asset purchases (LSAPs) range from "LSAPs played a significant role in supporting economic activity" 2 to "the expansion of assets has had very little impact on the economy." ${ }^{3}$

An argument against QE is that it side-steps the main goal of the policy itself, which is 
to stimulate the economy and generate consumer price inflation. Instead, it appears to merely cause asset price bubbles, and thereby becomes self-defeating.

As a positive side-effect, QE-1 (Nov. 2008) is credited as a prime factor for the bottomingout of the 2008 recession in the second half of 2009. And QE-2 (Nov. 2010) is widely believed to have led to a rise in the stock market at the end of 2010, which contributed to an increase in consumption and thereby stimulated economic activity.

As a negative side-effect, QE can fail to spur demand if banks remain reluctant to lend money to businesses and households. The QE policy is also widely believed to have led to an increase in the income and wealth inequality due to the effect it has on financial markets causing asset price inflation.

It has become clear by now that QE causes a reverse 'flight to quality', which could be called a 'flight to quantity', due to the low yields on T-Bills resulting from the policy. Whereas a flight to quality implies that investors seek less risk in exchange for lower profits, and therefore shift from private assets to government backed securities, during a flight to quantity institutional investors such as pension funds are seeking more risk in order to obtain higher returns. They move away from government bonds towards other, higher-yield investments. By driving up the price of firm stocks, this has contributed to an appreciation of asset market valuations, resulting in a reduction of systemic risks by bolstering the balance sheets of the banks.

In Europe the policy response has been less forthcoming. The ECB started Quantitative Easing only in January 2015, by initiating a programme to purchase Eur 60bn per month of Euro area bonds from Euro area institutions (estimated total costs of 1.1 trillion Euro). The stated policy goal of the Eurozone's QE policy is to return to inflation rates below but close to 2 percent. To this end, the threat of deflation across the Eurozone let Mr. Draghi to announce that the programme will continue "until we see a sustained adjustment in the path of inflation." 4 However, at the same time he announced that "What monetary policy can do is to create the basis for growth, but for growth to pick up, you need investment." (ibid.)

Hence, on the fiscal policy side, the European Commission and the European Investment Bank initiated the Investment Plan for Europe, and launched the European Fund for Strategic Investments (EFSI). The stated policy goal of this fund is that "Initial funding of Eur 21bn should result in total investment in strategic projects of at least Eur 315bn over the period 2015-2017 thanks to the Fund's potential to mobilise private investment." ${ }^{5}$ Thus, a main driver of this policy is the commitment to a belief that public investment will lead to a crowding-in of private investments.

\section{Related literature}

Our analysis is related to several streams of literature that discuss the linkages between real and financial cycles, the design of stabilization policies as well as the effects of credit market and banking regulations. Below we briefly review the work that is most closely related to our research agenda and methodological approach.

Business and financial cycles; Financial Instability Hypothesis

Empirical studies on how business cycles and financial cycles are interrelated find that recessions after a financial crisis tend to be longer and deeper than other recessions (Claessens et al., 2011). Schularick and Taylor (2012) find that a one standard deviation increase in the real growth rate of total private sector debt is associated to an increase in the probability of a financial crisis by approximately 2.8 percentage points. 
This evidence suggests that the duration and costs of recessions are determined by the interplay between financial and real variables that tend to be amplified through a financial accelerator mechanism. The presence of a financial accelerator opens up the possibility of fluctuations to be transmitted through the balance sheets of firms, households and banks.

We use these findings to investigate whether in our model there are similar relationships between the fluctuations in the credit market and the aggregate real variables. We then relate these to the strength of policy parameters of the credit regulations to investigate whether stronger credit regulations lead to shorter and more shallow recessions. From a social welfare perspective, the estimated costs of recessions will determine whether strong or weak credit regulations are preferable.

Other empirical studies go beyond viewing the credit market as a mere financial accelerator, and consider credit as an endogenous source of financial disturbances. This is in line with scholars such as Minsky (1978) and Kindleberger (2000) who view endogenously created credit bubbles and the accompanying increase in leverage as a cause of economic instability. Measuring leverage trends along the business cycles may then be a way to monitor the heightening risk of financial crises. In empirical testing of the Financial Instability Hypothesis (FIH), Schularick and Taylor (2012) find that lagged credit growth is the best predictor for future financial instability. This result thus supports the FIH in that a credit bubble is a precursor to instability.

Using data for 14 countries the authors find several trends for the post-WWII era (19452008). The data show an increase in financial instability is mainly caused by three factors: (i) expansion of the role of credit, (ii) higher leverage of banks' balance sheets, and (iii) increased policy intervention preventing a periodic deleveraging.

The first trend is that since 1945 bank loans have increased strongly relative to GDP, and relative to broad money (M2 or M3). The loan-money ratio grew by 2.19 percent per year indicating a much stronger dependence on bank credit in the economy.

A second trend is the increased leveraging evidenced by a shift to more risky assets on the balance sheets of banks. The proportion of safe, liquid, low-yield assets has been reduced in favour of more riskier, high-return assets. Since the safe assets can serve as a buffer to financial shocks in "bad times", this shift has weakened the banks' ability to withstand shocks.

The third and final trend is policy intervention. Due to the lessons learned during the Great Depression policy-makers have been more prone to act in financial crises. This has prevented a periodic deleveraging of the financial sector during the post-WWII period, and has implicitly allowed a growth of leverage to occur up to the financial crisis of 2007-8.

\section{Credit market regulations}

The new Basel III banking regulation calls for a 4.5 to 7 percent ratio of core equity tier-1 capital (CET1) to risk-weighted-assets, to be phased-in by 2019 (Basel Committee on Banking Supervision, 2013). This long gestation period is to ensure there are no shocks due to a sudden change in regulation. According to Admati and Hellwig (2013) this capital requirement is much too weak, and focusses attention on the wrong issues. They argue that banking regulation is now targeted at banks' assets, while it should be focussed on the banks' liabilities. In particular, banks should have more capital (a lot more) and less short-term debt. More capital would stabilize the financial system and prevent the large overhangs of short-term debt that now are causing fire sales of assets in the case of a liquidity crisis. One of the main problems they see is that bank debt is guaranteed by government, which provides the wrong incentives to banks to increase their risk-exposure and to run up their leverage ratios. The capital ratios that Admati 
and Hellwig advocate are more in the range of 20 to 30 percent of non-risk weighted assets, which stands in stark contrast to the current 4.5 percent of risk-weighted assets in Basel II and the future 7 percent in Basel III. Such high capital ratios are also not without historical precedent since in the $19 t h$ century banks funded themselves with 40 to 50 percent capital. Note however that other authors (cf., Calomiris, 2013) have pointed out that such historical comparisons are not entirely unproblematic since banks' equity ratios have changed dramatically over time, and a comparison should take into account the asset risks, as well changes in institutional arrangements. For instance, in the 19th and early 20th century banks did not have access to deposit insurance or a safety net such as tax-funded bail-outs.

A related argument deals with the positive impact that very strict banking regulations might have on aggregate economic outcomes. If banks are forced to create buffer stocks of capital, by so called dynamic loan loss provisioning, this ensures the supply of credit also during times of duress so it will stabilize aggregate output fluctuations.

A third argument considers the social costs of banking crises. A potential counter-argument against higher capital requirements is that this would be very costly and it would reduce the supply of funds available to lend to firms. Admati and Hellwig argue against this, by showing that the private costs for the banks of having sufficient amounts of equity are much smaller than the social costs of taxpayer-funded bail-out programmes. Also, if banks were to have more capital this does not reduce the funds available for lending in any way since it improves the confidence of the general public in the banking system as a whole and thereby contributes to financial system stability.

\section{Credit networks and interbank markets}

Particular emphasis on the role of credit markets for aggregate fluctuations is given in Delli Gatti et al. (2003, 2008) and Delli Gatti et al. (2011). An important aspect of their models is that they capture the linkages based on credit relationships between firms and banks, among firms in trade networks, and among banks in inter-bank networks. These properties allow to gain important insights into relevant mechanisms responsible for contagion effects and to explore implications of different types of bank and credit market regulations.

Ashraf et al. (2011) also explore the effects of different banking regulations, in a model of shop owners where market interactions are governed by search and matching processes. They study the role of banks both in normal times and in times of crises.

Krug et al. (2014) study the impact of the proposed Basel III regulations in an agent-based model with credit networks. They find that the positive joint impact of several microprudential policies to the resilience of the financial system is larger than the sum of the individual effects measured in isolation, that is, the effects of the policies are non-additive. This makes the important point that policies should be considered in unison, and it is important to study whether policies are mutually enhancing or detracting.

\section{Agent-based macroeconomics}

A number of recent contributions to the literature have developed closed macroeconomic models using an agent-based approach (e.g. Mandel et al., 2010; Dawid et al., 2014, 2015; Dosi et al., 2010, 2013, 2015). These models incorporate heterogeneity of different agent types (households, firms, banks) along various relevant dimensions (skill levels, capital stocks, financial variables). Furthermore, the behaviour of the agents is modeled with recourse to strong empirical foundations. As discussed extensively e.g. in Dawid et al. (2015) and Dosi et al. (2015), many 
of these models are able to replicate a large set of stylized facts at different levels of aggregation, and can be used to highlight the economic processes that generate these fluctuations. Agentbased macroeconomic models have a number of advantages over more standard macro models. Particularly relevant to our purpose is the notion that agent-based models are able to produce self-sustaining business cycle fluctuations by relying on the endogenous generation of shocks at the microlevel. This stands in stark contrast to many standard macroeconomic models, such as Real Business Cycle models and Neo-Keynesian models, which require a continuous stream of exogenous shocks to produce business fluctuations.

Several of the agent-based macroeconomic papers cited above focus on policy issues and highlight the advantages of an agent-based approach in this respect. In particular, considering the dynamics of the key variables of the different agents at the micro level allows to study in detail the mechanisms responsible for the short-run and long-run effects of policies and regulatory measures.

\section{The Model}

\subsection{Overall Structure}

The model describes an economy containing labour, consumption goods, capital goods, financial and credit markets. The economy is inhabited by numerous instances of different types of agents: firms (consumption goods producers and capital goods producers), households and banks. Additionally, there is a single central bank and a government that collects taxes and finances social benefits as well as potentially some economic policy measures. Finally, there is a statistical office (Eurostat) that collects data from all individual agents in the economy and generates aggregate indicators according to standard procedures. These indicators are distributed to the agents in the economy who might use them as input to their decision rules, and are also stored in order to facilitate the analysis of the simulation results. A graphical overview over the crucial parts of the model is given in Figure 1.

\section{[ADD FIGURE 1: "EuraceUnibi Model" ABOUT HERE]}

Capital goods of different quality are provided by capital goods producers with infinite supply. The technological frontier (i.e. the quality of the best currently available capital good) improves over time, where technological change is driven by a stochastic (innovation) process. Firms in the consumption goods sector use capital goods combined with labour input to produce consumption goods. Consumption goods are sold at local market platforms (called malls), where firms store and offer their products and consumers come to buy goods at posted prices. Labour market interaction is described by a simple multi-round search-and-matching procedure where firms post vacancies, searching employees apply, firms make offers and employees accept/reject. Wages of employees are determined, on the one hand, by the expectation the employer has at the time of hiring about the level of specific skills of the employee, and, on the other hand, by a base wage variable, which is influenced by the (past) tightness of the labour market and determines the overall level of wages paid by a particular employer. Banks collect deposits from households and firms and give credits to firms. The interest firms pay depends on the financial situation of the firm. The amount of the loan might be restricted by the bank's liquidity and

risk exposure. In case a bank is illiquid the central bank provides standing facilities through its discount window at a given base rate. It also pays interest on the banks' overnight deposits and might provide fiat money to the government. 
Finally, there is a financial market where shares of a single asset are traded, namely an index bond in which all firms in the economy participate (banks, consumption goods firms and investment goods firms). The dividends paid on each share of the index bond at a certain point in time is determined by the total dividends paid by all firms. This simple representation of a financial market is meant as a generating mechanism for an asymmetric wealth distribution. It captures the important feedback from firm profits to households' wealth, where the fluctuations in dividends only affect the wealth of households owning shares.

Since the focus of this paper is on credit market regulation, more detail on the credit market is given in the next sections. More extensive model specifications for the other markets can be found in (Dawid et al., 2011b, 2012).

\subsection{Firm sequence of activities}

Each firm proceeds through the following sequence of economic activities:

1. On the firm's idiosyncratic activation day the firm starts its production cycle with production planning. The production plan consists of planned output based on historical observations and the results of market research. Based on the production plan the firm determines its planned input demand for capital and labour.

2. Financial management of the firm. The firm computes the costs of production and the costs for financing its commitments. If the internal resources are insufficient the firm tries to finance externally by requesting credit.

3. Credit market with direct firm bank linkages opens. The banks provide credit by servicing the loan request on a first come first serve basis. The bank decides on the credit conditions for the applying firm (interest rate and amount of credit provided) depending on the firm's financial situation. If the credit request is refused, or not fully accepted, the firm has to reduce its planned production quantity.

4. Bankruptcy of two types could occur. If the firm is credit constrained to such extent that it is not able to pay the financial commitments it becomes illiquid and illiquidity bankruptcy is declared. If at the end of the production cycle revenues are so low that the firm has negative net worth, the firm is insolvent and insolvency bankruptcy is declared. In both cases it goes out of business, stops all productive activities and all employees loose their jobs. The firm writes off a fraction of its debt with all banks with which it has a loan and stays idle for a certain period before it becomes active again.

5. Capital goods market opens. Depending on the amount of financing secured by the firm, it makes physical capital investments. This consists of a vintage choice where the productivity of the capital stock is updated if new vintages are installed.

6. A decentralized labour market opens where firms with open vacancies are matched to unemployed households. The matching is based on the firm's wage offer and on the employee's skill level and reservation wage.

7. Production takes place on the firm's activation day. After production is completed, the output is distributed to local malls. Firms offer goods at posted prices with price revisions occurring once a year. 
8. At the end of the production cycle the firm computes its revenues, and updates its income statement and balance sheet. It pays taxes, dividends, interests and debt installments. It checks if net worth is negative and if so, declares bankruptcy. Otherwise it continues with the next production cycle.

\subsection{Consumption goods sector}

Consumption goods are produced by the firms once in a month on their activation day. The activation days of firms are asynchronously distributed over the month. The consumption goods are homogeneous regarding quality, but horizontally differentiated and heterogeneous in prices. Each firm conducts a detailed production planning containing the calculation of the vertically differentiated input factors capital and labour. Planned production quantities and prices are determined by using estimated residual demand curves obtained from simulated purchase surveys on a test market. In particular, firms set planned production quantities and prices in order to maximize the expected discounted profits over their planing horizon taking into account the estimated marginal costs and the elasticity of demand. Firms store the produced goods in a mall. Each household visits the mall once a week but not all households visit the mall on the same day of the week. They spend their consumption budget in order to purchase consumption goods. Since the consumption goods are homogeneous regarding the quality but heterogeneous in price, less expensive goods are more likely to be chosen. The decision which good to buy is described using a logit-choice model with a strong empirical foundation in the marketing literature (see e.g. Malhotra, 1984). The parameter $\gamma$ determining the strength of the influence of prices on the consumers product choice is a crucial model parameter in this respect. A large value of $\gamma$ corresponds to strong price sensitivity of consumers, which implies intensive competition between the consumption good producers. As will be discussed below, such strong competition induces more unstable and volatile economic dynamics compared to a scenario with smaller $\gamma$, where firms have more market power and on average gain higher profits.

Employees are heterogeneous in their general skill levels (general education) and an endogenously evolving specific skill level (job-related knowledge). The specific skill level depends on the technology in use by the firm they work for. The specific skills increase over time during the production process through learning on-the-job and investments in new technology vintages by the firm impute a new learning phase. Employees learn, that is, improve their specific skill levels, by using the current machinery in the firm (see e.g. Argote and Epple, 1990). The speed of learning depends positively on the general skill level of the employee, and learning only occurs when the productivity of the machinery exceeds the specific skill level of that employee, thus closing the so called skill-gap.

The production technology in the consumption goods sector is represented by a Leontief production function in which the input factors are used in fixed proportion: one unit of capital is used by one employee. There is complementarity between the productivity of the inputs, that is, the average productivity of the mix of capital vintages currently in use by the firm and the average specific skills of the employees currently employed by the firm. The effective productivity of one unit of capital is the minimum of the productivity of the physical capital and the average productivity of labour.

\subsection{Investment goods sector}

Investment goods ${ }^{6}$ are produced by one investment goods producer. The investment goods producer offers different vintages of the investment good with different qualities on every day. The supply of each vintage is infinite. In order to simplify the model at this point it is assumed 
that the investment goods producer is able to produce without any input factors. The introduction time of new vintages with improved quality (higher productivity) follows an exogenous stochastic process. The quality of a machine determines the maximal productivity when used by employees with sufficiently high specific skills. The investment goods producer expands the set of vintages on offer as soon as a new vintage becomes available. Prices for the vintages are determined by the investment goods producer using a combination of a cost-based approach and a value-based approach. In order to close the model the revenues of the investment goods producer are paid out as dividends to the households.

Consumption goods producers need investment goods as an input factor to their production process. They select a vintage from the list if they want to expand or replace their capital stock. To make a vintage choice firms estimate the costs and expected future benefits of the different vintages over their planning horizon, depending on the skill distribution of their workforce. The probability to select a certain vintage is then determined by a logit model based on the ratio of the benefit and the costs of each vintage.

\subsection{Labour market}

The labour demand is solely determined by the consumption goods producers. If a firm reduces its output a corresponding number of employees are dismissed such that the new workforce matches the planned output. In case of an expansion of production the firm posts vacancies that contain wage offers. If the firm cannot fill all of its vacancies due to a tight labour market or due to search frictions, it increases the wage offer to attract more employees. Only unemployed households search for jobs, so there is no on-the-job search. An unemployed household searches actively on average on two randomly chosen days per month. She considers the wage offers of a randomly chosen subset of firms that have posted vacancies and compares these to her reservation wage. If the wage offer exceeds her reservation wage she sends in an application. The maximum number of applications per person per month is fixed exogenously.

For the firm, if the number of applicants is below the number of vacancies, the firm sends job offers to all applicants. If the number of applicants exceeds the number of vacancies the firm sends job offers to as many applicants as there are vacancies to fill. Firms prefer applicants with higher general skills. Every unemployed household ranks the incoming job offers according to the wage offer and the highest ranked job offer is accepted. This algorithm is aborted after two iterations, which implies that not all firms necessarily may fill all their vacancies and/or not all unemployed households find a job. This implies labour market frictions and a possible rationing of firms. In addition, in each period any employment relationship can be dissolved at random with some small constant probability such that a certain rate of labour turnover is ensured even in the absence of output adjustments by the firms.

\subsection{Financial management}

At the end of each production cycle (one month) the firm computes its income statement to determine its profits. Table 1 shows the balance sheet of the firm. The realized profit of a consumption goods producer equals the sales revenues plus interest received on bank deposits minus the production costs (fixed and variable costs). Hence, $\pi_{i, t}$ is determined at the end of 
month $t$ as:

$$
\begin{aligned}
\pi_{i, t} \quad & =R_{i, t}+r^{b} M_{i, t}-\left(C_{i, t}^{F i x}+C_{i, t}^{V a r}\right) \\
& =R_{i, t}+r^{b} M_{i, t}-\left(\sum_{l=1}^{T^{L}} \frac{p_{t-l}^{i n v} \cdot I_{t-l}}{T^{L}}+\sum_{l=0}^{T^{L}} r_{i, t-l}^{b} L_{i, t-l}^{b}\right)-\left(W_{i, t}+\frac{p_{t}^{i n v} \cdot I_{t}}{T^{L}}\right) .
\end{aligned}
$$

The fixed costs are the fixed capital expenditures over the previous periods $\left(t-T^{L}, \ldots, t-1\right)$ and the interest due on loan contracts over the periods $\left(t-T^{L}, \ldots, t\right)$ that includes the loan obtained at the start of this period $t$. Here $T^{L}$ represents the length of a loan period (typically multiple months, $T^{L}=18$ ). The variable costs consist of the wage bill $W_{i, t}$ and the fraction of total investments that are accounted for in the current month. If profits are positive, the firm pays taxes and dividends according to the rates $\tau$ and $d$, respectively. ${ }^{7}$

\subsection{Dividend payout policy}

Define average net earnings (after-tax profits) over the last $n$ months as $\left\langle\pi_{i}\right\rangle_{n}=\frac{1}{n} \sum_{s=0}^{n-1} \pi_{i, t-s}$. The monthly dividend payout is based on the average net earnings over the previous 4 months, using the dividend rate $d(d=70$ percent):

$$
\operatorname{Div}_{i, t}=d \cdot\left\langle\pi_{i}\right\rangle_{4}
$$

\subsection{Firm credit demand}

The total liquidity needs to finance the next production cycle consist of the planned production costs, i.e. the new wage bill and planned investments. Besides expenses related to production, the firm also needs to finance the financial commitments that are carried over from the previous production cycle, such as taxes and dividends on profits, debt installments and interest payments. The total expenditures that need to be financed at the start of the new production period $t+1$ are as follows:

$$
\begin{aligned}
E_{i, t+1} & =W_{i, t+1}+p_{i, t+1}^{i n v} \cdot I_{i, t+1}+\tau \max \left[0, \pi_{i, t}\right]+\operatorname{Div}_{i, t} \\
& +\sum_{l=0}^{T^{L}} \frac{L_{i, t-l}}{T^{L}}+\sum_{l=0}^{T^{L}} r_{i, t-l}^{b} \cdot L_{i, t-l} .
\end{aligned}
$$

The last two terms represent debt installments and interest payments on old loan contracts for the previous periods $\left(t-T^{L}, \ldots, t\right)$ that now need to be serviced. Note that by using this formulation, we allow the firm to obtain a new loan to pay for its taxes and dividends of the previous period. Note also that dividends are paid out of after-tax firm profits, as is usual in the tax code. The demand for bank loans is the remaining part of the total liquidity needs that cannot be financed internally from the payment account (all variables below are determined at the start of period $t+1)$ :

$$
L_{i, t+1}=\max \left[0, E_{i, t+1}-M_{i, t+1}\right] .
$$

Firms shop around for credit conditions (the interest rates are variable, the debt repayment period is fixed to 18 months) and request the same amount of credit from a random subset of banks (by default, we let a firm select 2 out of 20 banks at random). Given the credit conditions, the firm then selects the bank with the lowest interest rate offer. Thus, this generates an endogenous network of random credit relationships between banks and firms with some persistence due to the long debt repayment period. 


\subsection{Firm bankruptcy: Entry and Exit}

The occurance of firm bankruptcy is driven in the model by either an internal or an external cause. The internal cause is that a firm fails on its own account and net worth becomes negative. In this case we speak of firm insolvency. The external cause is due to credit rationing and we speak of firm illiquidity.

- Insolvency bankruptcy: The firm updates its balance sheet and checks for insolvency at the end of the production cycle when it has received the revenues from this month's sales. If the firm equity becomes negative it is insolvent and goes out of business. It has to perform a debt restructuring before it can continue operations. We resolve the insolvency by reducing the firm's debt, by rescaling it based on the current total assets, i.e. by means of a debt-equity transformation (see Section 3.10 for details).

- Illiquidity bankruptcy: After visiting the credit market the firm was unsuccessful in raising all required external funds. It is therefore unable to pay its financial commitments, i.e., taxes, debt instalments and interests. Firm equity is positive but it does not have enough liquidy to continue operations. It should first raise enough funds to become liquid again. We resolve the illiquidity by reducing the firm's debt, by rescaling it based on the current debt (see Section 3.10 for details).

The effects of bankruptcy are that a firm fires all employees who then receive unemployment benefits from Goverment. The firm suspends all production activities for a year. At the end of this idle period the firm re-enters and production is restarted. The physical capital stock remains inside the firm, but is unproductive during the idle period. The local inventory stock is destroyed, representing the economic loss due to bankruptcy. Finally, there is a debt renegotiation with the banks. For each loan, the firm defaults on a fraction and the bad debt should be written off from the bank's balance sheet at which the loan was obtained.

\subsection{Debt deleveraging and restructuring}

Debt deleveraging is modelled by re-scaling the total debt. To make it easier for re-entering firms to obtain new loans we should improve their debt-equity ratio and lower their risk of default. This makes it more likely for a bank to accept any future loan requests from such a debt-restructured firm.

In case of an insolvency, the new target debt $D^{*}$ is set lower than total assets $A$. The debt rescaling parameter $\varphi$ is assumed to be constant across all firms and over time:

$$
D^{*}=\varphi A \quad \text { with } \quad 0 \leq \varphi \leq 1 .
$$

After debt restructuring, the equity of the restructured firm is now positive, $E^{*}=(1-\varphi) A>$ 0 . The debt/equity-ratio after rescaling is given by the constant: $D^{*} / E^{*}=\varphi /(1-\varphi)$.

In case of illiquidity, the firm does not need to renegotiate its debt per se, since $D$ is already lower then $A$ and equity is still positive. However, since the firm is unable to pay its financial commitments it should raise new funds. It could do so either on the credit market or in the stock market by means of issuing new shares, but since we have precluded firms from issuing new shares (for reasons of simplicity) we also allow illiquid firms to write down part of their debt. In contrast to insolvent firms, illiquid firms do not rescale their debt as a fraction of assets, but as a fraction of the original debt:

$$
D^{*}=\varphi D \quad \text { with } \quad 0 \leq \varphi \leq 1,
$$


Table 1: Firm balance sheet.

\begin{tabular}{|l|l|}
\hline Assets & Liabilities \\
\hline$M_{i}:$ liquidity deposited at a given bank & $D_{i}:$ debts to banks \\
Inv $v_{i}:$ value of local inventories at malls & $E_{i}$ : equity \\
$K_{i}:$ value of physical capital & \\
\hline
\end{tabular}

with new equity given by $E^{*}=A-\varphi D>E$ and a new debt/equity-ratio $D^{*} / E^{*}=\varphi D /(A-\varphi D)$. Since setting a lower value for the debt/equity-ratio improves the firm's chances of getting new loans in the future, the debt rescaling parameter $\varphi$ must be set to low values $\varphi \leq 0.5$ to ensure that $D^{*} / E^{*} \ll D / E$.

\subsection{Banking sector}

Commercial banks offer demand deposit accounts (giro payment accounts) and lend to borrowers at varying interest rates. The firms and households select a random bank to deposit their savings and this deposit bank remains fixed for each agent throughout the simulation. Only firms can borrow, and they can initiate a credit relationship with any commercial bank (there is no relationship banking with a house bank). Firms can have more than one loan at a multitude of banks, but a new loan request is always served (partially or in full) by just one bank, when the credit request is successful. It is possible that a new loan request will be partially filled, but then no spillovers of additional loan requests to other banks occur.

The decision whether or not a credit relationship is established is two-sided: both the firm and the bank have to agree, and the credit conditions will depend on the balance sheet of both firm and bank, subject to capital requirement and liquidity constraints. Both the equity of the bank and the leverage (debt-equity ratio) of the firm enter into the determination of the interest rate.

Over the course of time, a firm may have a heterogeneous debt portfolio with a multitude of banks, each charging a different interest rate. Similarly, the bank's credit relationships evolve over time and it can charge different interest rates to different firms, depending on the financial indicators.

There are three reasons why a bank may stop providing new loans: (i) it has violated its liquidity constraint (the central bank reserve ratio): in this case it needs to borrow reserves from the Central Bank at an overnight rate. If liquidity is positive again the bank willl automatically redeem its Central Bank debt. (ii) it violates the capital adequacy ratio, with its equity is still positive. The bank is not insolvent, but halt its credit supply. (iii) similar to (ii), but now its equity is negative. This case can occur due to bad debt that is written off. The bank is not declared bankrupt, but the supply of new liquidity to firms is halted. It continues to service the demand deposit accounts (withdrawals and interests) and receives interest and debt installment payments that may lead to a recovery of equity back to positive values.

\subsubsection{Bank balance sheet}

The balance sheet of the bank is shown in Table 2. Its assets consist of central bank reserves and outstanding loans to firms. The liabilities are household and firm deposits, and reserve debts to 
Table 2: Bank balance sheet.

\begin{tabular}{|l|l|}
\hline Assets & Liabilities \\
\hline$M^{b}:$ liquidity (central bank reserves) & $M_{h}^{b}:$ household demand deposits \\
& $M_{i}^{b}:$ firm demand deposits \\
& $D_{i}^{b}:$ central bank debt \\
& $E^{b}:$ equity \\
\hline
\end{tabular}

the Central Bank. Banks receive interest and debt instalment payments on their outstanding loans to firms, and pay dividends at a constant rate. They do not purchase government bonds, and they do not purchase shares of other firms or banks. The bank can freely draw advances of central bank reserves from the discount window at the Central Bank and all banks' reserves are deposited at the Central Bank overnight on which the Central Bank pays the base interest. If the bank has a debt to the Central Bank, it pays the base interest rate to the Central Bank.

The deposit interest rate $r^{b}$ that the bank pays on demand deposit accounts is lower than the base rate $r^{E C B}$, while the interest rate on loans to firms $r_{i}^{b}$ is higher than the base rate $\left(r^{b}<r^{E C B}<r_{i}^{b}\right)$. This ensures that banks can make a profit. The deposit interest rate $r^{b}$ is determined as a mark-down on the base rate, while the interest on loans $r_{i}^{b}$ depends on the firm-specific balance sheet, in particular on the probability of default. The base rate of the Central Bank is constant by default. It is made endogenous only in case of monetary policy experiments.

\subsubsection{Bank accounting}

Bank reserves fluctuate with deposits and withdrawals, interest payments, and finally also with taxes and dividends. The net profits (or losses) after taxes and dividends are added to the reserves and held at the Central Bank. Profits $\pi_{t}^{b}$ at the end of month $t$ are determined by:

$$
\begin{aligned}
\pi_{t}^{b} & =\sum_{i} r_{i}^{b} L_{i t}^{b}-r^{b}\left(\sum_{h} M_{h t}^{b}+\sum_{i} M_{i t}^{b}\right)+r^{E C B}\left(M_{t}^{b}-D_{t}^{b}\right), \\
M_{t+1}^{b} & =M_{t}^{b}+\Delta M_{h t}^{b}+\Delta M_{i t}^{b}+(1-\tau) \max \left[0, \pi_{t}^{b}\right]-d^{b}(1-\tau) \max \left[0, \pi_{t}^{b}\right] .
\end{aligned}
$$

The bank's profits consist of the margin between interests on loans and interests on deposits, plus (minus) any interest paid by (to) the Central Bank on overnight reserves (reserve debt). In case of positive profits, the bank pays taxes and dividends at rates $\tau$ and $d^{b}$, resp. The net mutations of the demand deposit accounts are given by $\Delta M_{h, t}^{b}=M_{h, t}^{b}-M_{h, t-1}^{b}$ and $\Delta M_{i t}^{b}=M_{i, t}^{b}-M_{i, t-1}^{b}$, resp.

It is possible that due to deposit mutations the bank's reserves become negative. We assume the Central Bank follows a fully accommodating monetary policy by providing liquidity as needed. The banks thus have a standing facility from which they can draw advances freely. If bank liquidity is positive, the bank automatically pays off its Central Bank debt and receives interest on overnight deposits. If liquidity is negative, the bank automatically draws on Central Bank debt, sets $M_{t+1}^{b}=0$ and $D_{t+1}^{b}>0$ and pays daily interest to the Central Bank. 


\subsubsection{Bank credit supply and risk-taking behaviour}

The bank's ability to provide credit is restricted by a Capital Adequacy Requirement (CAR) and the Reserve Requirement Ratio (RRR). The bank's risk-taking behaviour depends on its current level of exposure to default risk and the capital requirement.

Firms select banks at random in each production period, so the credit market can be viewed as a random matching process. The bank records several characteristics of the applying firms: total debt, size of credit requested, firm equity, and additional risk exposure. These attributes enter into the risk assessment of the bank and the loan conditions offered to the firm, consisting of size and interest rate for the loan. The firm then selects the bank with the lowest interest rate offer.

On a daily basis, the banks rank their stream of credit requests in ascending order of risk exposure. The least risky credit request of the current day is considered first, but different firms have different activation days during the month, so each new day sees new firms requesting loans to the same bank. If a healthy, financially sound firm requests a loan one day after an unhealthy, financially unsound firm has already obtained a loan with a large risk exposure, the healthy firm may see itself credit rationed due to limits on the banks' risk exposure.

\subsubsection{Probability of Default}

The firm's probability of default (PD) depends on the creditworthiness of the firm, measured by the debt-to-equity ratio (including the new debt). Following the internal risk-based (IRB) approach of the Basel Accords, there is a minimum risk-weight that sets a floor-level for the probability of default at 3 basis points (0.03 percent). We assume a bank associates the following PD to a loan of size $L_{i t}:{ }^{8}$

$$
P D_{i t}=\max \left\{3 \times 10^{-4}, 1-e^{-\nu\left(D_{i t}+L_{i t}\right) / E_{i t}}\right\} .
$$

The rule is parametrized by a parameter $\nu(\nu=0.1)$ that weights the impact of the debt-toequity ratio on the probability of default.

\subsubsection{The updating frequency of the Probability of Default}

The updating frequency of the risk weights depends either on the bank's own internal risk-model, or on the updating frequency of the rating agencies' credit ratings, if the bank uses such external ratings. An important question is how often banks should update the risk-weights, or how long banks should retain the same credit ratings for outstanding loans

In our model, the banks use an updating frequency of one month since the firms have an 18 month debt repayment period, and send monthly debt installments to the bank. Also, the bank is immediately informed if the firm becomes insolvent. Therefore it seems reasonable, and from a regulatory perspective also prudent, to let the bank update the PD as frequent as possible, given the information it has on the creditworthiness of their debtors.

Furthermore, there are no costs to computing the new risk weights, and there are no monitoring costs for the banks. Hence, we have assumed perfect information and the highest possible updating frequency. This means that in the context of our model, banks adjust their risk weights on a daily basis, whenever a firm makes a loan repayment. Each individual firm makes monthly payments, but due to the asynchronous nature of the firms' production plans, each firm has a different activation day, so that in the end the bank receives daily updates. It takes one month for the bank to have adjusted all the risk weights on its loan portfolio, but at each moment in time the banks in the model have perfect information about the value of their RWAs. 


\subsubsection{Credit risk}

We assume there is no collateral for debt, hence debt is unsecured and the expected loss given default (or LGD) is one hundred percent of the loan. Due to this assumption, the credit risk or Exposure at Default (EAD) of the loan is simply the probability of default times the value of the loan:

$$
E A D_{i t}^{b}=P D_{i t} \cdot L_{i t}
$$

The total risk exposure of the bank is now simply the sum of risk-weighted assets across the entire loan portfolio:

$$
R W A_{t}^{b}=\sum_{i=1}^{F} \sum_{k=0}^{K(i)} P D_{k t} \cdot L_{k t},
$$

where the index $i$ runs over all firms, and index $k=0, \ldots, K(i)$ over loans of firm $i$ with bank $b$.

\subsubsection{Interest rate rule}

The interest rate offered to a firm is an increasing function of the credit risk reflecting the risk premium that the bank charges to more risky, less financially sound firms. The credit risk posed by firm $i$ enters into the loan conditions as a mark up on the Central Bank base interest rate. The weight of the credit risk in the interest rate can be calibrated by a behavioural parameter $\lambda^{B}$ that is the same across all banks $\left(\lambda^{B}=3\right)$. Furthermore, the time-varying operating costs are captured by a random variable $\epsilon_{t}^{b}$, which is uniformly distributed on the unit interval. ${ }^{9}$

$$
r_{i t}^{b}=r^{E C B}\left(1+\lambda^{B} \cdot P D_{i t}+\epsilon_{t}^{b}\right), \text { with } \epsilon_{t}^{b} \sim U[0,1] .
$$

\subsubsection{Capital Adequacy Requirement}

Each bank is required to satisfy a minimal capital adequacy ratio, implying that banks have to observe a limited exposure to default risk. That is, bank equity (core capital) must be greater or equal to a fraction $\kappa$ of the value of its risk-weighted assets. This assumption is based on Basel II/III capital requirements, where $\kappa$ is between 4 and 10.5 percent. The bank's total exposure to credit risk is restricted by $\alpha:=\kappa^{-1}$ times the equity of the bank:

$$
E_{t}^{b} \geq \kappa \cdot R W A_{t}^{b} \quad \text { i.e. } \quad R W A_{t}^{b} \leq \alpha \cdot E_{t}^{b}
$$

Here $E_{t}^{b}$ is bank equity (core capital), $R W A_{t}^{b}$ is the value of risk-weighted assets, $\kappa$ is the capital adequacy ratio, and $\alpha:=\kappa^{-1}$ is the maximum leverage in terms of equity to risk-weighted assets. If the constraint is violated the bank stops providing new loans. Pre-existing loans are still administered, firms continue to pay interest and debt installments, and the demand deposits of account holders continue to be serviced. From this we derive a credit risk exposure "budget" $V^{b}$ that is still available to fund firms:

$$
V_{t}^{b}:=\alpha \cdot E_{t}^{b}-R W A_{t}^{b}
$$

The supply of credit risk in the current period is restricted to this exposure budget $V^{b}$. Firm $i$ receives its full credit whenever the bank's total credit risk exposure remains below this limit and is fully rationed when the loan would exceed the risk limit. In terms of the exposure budget $V^{b}$ the credit offer reads: ${ }^{10}$

$$
\bar{\ell}_{i t}^{b}= \begin{cases}L_{i t} & \text { if } P D_{i t} \cdot L_{i t} \leq V_{t}^{b} \\ 0 & \text { if } P D_{i t} \cdot L_{i t}>V_{t}^{b}\end{cases}
$$


Bank risk exposure is positively correlated to the capital adequacy ratio $\alpha$. Higher $\alpha$ means more risk is allowed, hence banks have at their disposal a greater budget of excess risk exposure and will tend to give out more risky loans.

\subsubsection{Reserve Requirement}

The banks must observe a minimum Reserve Requirement Ratio (RRR), that is, reserves must exceed a fraction $0 \leq \beta \leq 1$ of total deposits of households and firms:

$$
M_{t}^{b} \geq \beta \cdot D e p_{t}^{b}, \text { where } D e p_{t}^{b}=M_{h t}^{b}+M_{i t}^{b} .
$$

From this an excess liquidity "budget" of the bank is derived as:

$$
W_{t}^{b}:=M_{t}^{b}-\beta \cdot D e p_{t}^{b} \geq 0 .
$$

Note that the reserve requirement is modelled here as a behavioral constraint and holds in addition to the bank's capital constraint given in (14). That is, we assume the bank anticipates the requirement, and therefore restricts its lending policy accordingly. The rationale behind this rule is that banks restrict their supply of credit to the excess liquidity they still have available. In this way, we capture the behaviour that if a bank approaches the minimum reserve level, it starts to ration firms with the highest demand for liquidity, and the rationing becomes more stringent as the excess liquidity declines.

If the excess liquidity budget is sufficient to provide a firm with its requested credit, then it is serviced in full. Otherwise it is partially credit rationed such that the bank attains its minimum reserve requirement. In case of partial rationing, the granted loan size is given by: ${ }^{11}$

$$
\ell_{i, t}^{b}= \begin{cases}\bar{\ell}_{i, t}^{b} & \text { if } W_{t}^{b} \geq \bar{\ell}_{i, t}^{b} \\ \phi \cdot \bar{\ell}_{i, t}^{b} & \text { if } 0 \leq W_{t}^{b} \leq \bar{\ell}_{i, t}^{b} \\ 0 & \text { if } W_{t}^{b}<0\end{cases}
$$

Here $\bar{\ell}_{i, t}^{b}$ is the constrained credit demand resulting from applying the CAR-constraint in (16). The fraction $\phi$ is such that the new reserves (incl. the granted loan) exactly exhausts the RRR constraint:

$$
\left\{\phi:\left(M_{t}^{b}-\phi \cdot \bar{\ell}_{i, t}^{b}\right)-\beta \cdot D e p_{t}^{b}=0\right\} \Leftrightarrow \phi=\frac{M_{t}^{b}-\beta \cdot D e p_{t}^{b}}{\bar{\ell}_{i, t}^{b}}=\frac{W_{t}^{b}}{\bar{\ell}_{i, t}^{b}} .
$$

\subsection{Rationing effects}

The credit rationing is caused either by banks' capital requirements becoming binding (an equity effect) or by its reserve constraint (a liquidity effect). We look at both mechanisms in turn in Figure 2. Suppose F1 is a financially unsound firm with a high default risk and a high liquidity demand. B1 is a bank to which F1 requests a loan. The bank(s) B2 are other banks at which F1 has an existing debt. The other firm(s) F2 are financially sound firms with low risk of default and low liquidity demand.

The figure illustrates how the equity constraint and the liquidity constraint work differently as transmission channels of financial instabilities. First consider the left panel: Suppose that B1 has a tight liquidity constraint and firm F1 has a high liquidity demand, and is therefore credit rationed by B1. F1 becomes illiquid, causing it to write off debt with B2. This reduces B2's equity, but not its liquidity. Therefore F2 can still receive a loan from B2. The financial contagion 
Table 3: Parameter sensitivity analysis.

\begin{tabular}{|c|rrrrrrrrrr|}
\hline$\alpha \in A$ & 1 & 2 & 4 & 6 & $\mathbf{8}$ & 10 & 12 & 16 & 24 & 32 \\
\hline$\beta \in B$ & 0 & 0.01 & 0.02 & 0.05 & $\mathbf{0 . 1 0}$ & 0.20 & 0.50 & 0.90 & 0.99 & 1.00 \\
\hline$\gamma \in C$ & 12 & 14 & 18 & $\mathbf{1 8 . 5}$ & 19 & 19.5 & 20 & 22 & 24 & 26 \\
\hline$r^{E C B}$ & 0 & 0.001 & 0.0025 & 0.005 & 0.0075 & $\mathbf{0 . 0 1}$ & 0.02 & 0.03 & 0.04 & 0.05 \\
\hline
\end{tabular}

is contained by the stringent liquidity constraint, that rations F1 so that it cannot further increase its leverage. This liquidity effect can be associated to the bank lending channel. There is no negative feedback from the liquidity constraint on bank B1 itself, and more importantly there is no contagion effect on the liquidity constraint of the other banks. The fact that B1 restricts liquidity does not affect the liquidity provision of the other banks B2 to the rest of the economy.

Now consider the right panel in Fig. 2: Suppose B1 now has a tight equity constraint. Since F1 has a high default risk it is again credit rationed by B1. Now F1 writes off debt with B2, this affects the equity of B2, which is under the same strict regulatory regime as B1. Hence, B2 restricts lending to all firms, including F2, even though it has a low default risk. The financial contagion is not contained, but rather is transmitted and amplified through the balance sheets.

The equity effect is associated to the balance sheet channel, since there is a balance sheet contagion from bank B1 to bank(s) B2, and this could lead to a balance sheet recession (cf. Koo, 2009, 2010). The effect is a self-reinforcing mechanism that makes it more restrictive. Once it becomes binding it causes firm illiquidities, which cause debt write-offs, which reduce bank equity even further. Such pro-cyclical effects are absent with the liquidity constraint. Another difference is that for the liquidity constraint the credit demand is partially rationed, whereas for the equity constraint it is fully rationed (when the loan request exceeds the riskexposure budget). The third difference is that the ECB provides additional liquidity as soon as the liquidity constraint becomes binding, due to its accommodating policy, whereas it does not provide additional capital when the equity constraint becomes binding.

\section{[ADD FIGURE 2: "Constraints" ABOUT HERE]}

\section{Results}

\subsection{Methodology and Experimental Design}

The simulation methodology consists of a Markov Chain Monte Carlo method (MCMC) with batch runs for each parameter setting. Before running the policy simulations, we generate a transient under a stable scenario, in order to have a stable starting point. The transient is ignored in the policy analysis. In the stable benchmark scenario, the parameter $\gamma=12$ indicates that the competitive pressure on firms in the consumption goods sector is relatively low, i.e. the consumers' price sensitivity wrt. price differences between the firms is low, resulting in high profit margins and low debt. The parameter $\alpha=10$ indicates that the CAR constraint is nonstringent, and will be non-binding most of the time. Finally, the parameter $\beta=0.10$ indicates that the RRR constraint is non-stringent, and will also be non-binding most of the time.

\subsection{Parametrization and empirical calibration}

The soundness or robustness of financial and non-financial institutions can be measured by several financial ratios. A good indicator for the financial robustness is the equity-asset ratio 
which is the opposite of the leverage ratio: $E_{i} / A_{i}=1-D_{i} / A_{i}$. For the financial soundness of banks, the equity-to-risk-weighted-assets ratio $E^{b} / R W A^{b}$ indicates the point at which the capital adequacy requirement becomes binding. When the equity-to-risk ratio falls below the adequacy ratio $\kappa$, the constraint is binding, i.e. when $E^{b} / R W A^{b} \leq \kappa$.

In order to obtain a rough empirical calibration for the values of the parameter $\alpha$ in the capital adequacy requirement, we use an empirical study by Hanson et al. (2011, p.39), in which empirical data on the E/A-ratio of US banks are provided. Historical values for the period 1840-2009 are shown to vary between 4 and 55 percent, and for the period 1976-2009 values varied between 4 an 14 percent. For the period 1996-2009, the equity-to-risk-weighted-assets ratio of US banks varied between 8 and 20 percent, which corresponds in our model to $\alpha=12.5$ and $\alpha=5$, resp.

To convert the equity-to-total-assets ratio into the equity-to-risk-weighted-assets ratio, a rule of thumb is to multiply by two, assuming the average risk weight is 0.5 (Ratnovski, 2013, p.66). Hence, a 4 percent equity-to-total-assets ratio corresponds to 8 percent equity-to-risk-weightedassets, and $\alpha=12.5$ in our model. And a 55 percent equity-to-total-assets ratio corresponds to a 110 percent equity-to-risk-weighted-assets, or $\alpha=0.9$ (i.e., risk-weighted assets covered by more than 100 percent of equity). Therefore the empirical range for the $\alpha$-values lies between 1 and 12.5 .

The Basel Committee on Banking Supervision (BCBS) has proposed the following Basel III phase-in arrangements from 2013 to 2019 (Basel Committee on Banking Supervision, 2013). The Minimum Common Equity Capital Ratio is 4.5 percent, i.e. the Common Equity Tier-1 capital (CET1) should be 4.5 percent of the value of risk-weighted assets. In addition, there is the mandatory Capital Conservation Buffer of 2.5 percent, totaling 7 percent of common equity capital. The minimum total capital ratio is 8 percent, consisting of Tier- 1 and Tier- 2 capital. On top of that, the national regulatory authorities are allowed to levy a discretionary Countercyclical Buffer on Globally Systemically Important Banks, the so called G-SIBs, of between 1 and 2.5 percent (totaling 10.5 percent of Common Equity Tier-1 capital).

For the parameter values of $\alpha$, these percentages $4.5,7,8$, and 10.5 correspond to $\alpha=22$, 14.4, 12.5 and 9.5, respectively. The theoretically proposed range of $\alpha$ therefore lies between 9.5 and 22. To take into account both the empirical data and the Basel III regulatory scheme as proposed by the BCBS for 2019, we calibrated our simulations to $\alpha$-values that lie between 2 and 32 .

To obtain an empirical calibration for the values of the parameter $\beta$ in the reserve requirement, we use the current values as set by the Central Banks around the world. In Canada, Australia, New Zealand, the U.K. and Sweden there is no reserve requirement, while in China it is 19.5 percent (as of Feb. 2015). In the U.S. it can be 0, 3 or 10 percent, depending on the net transaction accounts at the depository institution. For the Eurozone the reserve requirement is 1 percent. Finally, there is the Chicago Plan for Monetary Reform (Douglas et al., 1939), in which the authors call for a 100 percent reserve requirement.

In order to do justice to this wide range of variability, we did not calibrate the value of $\beta$, but instead used the full range of values between 0 and 100 percent. The parameter settings in Table 3 are the combinations used for the policy analysis, varying from non-binding to strongly-binding capital and liquidity constraints, respectively. With $\alpha \in A, \beta \in B$ we explore a $10 \times 10$-grid. The parameters $\gamma=18.5$ and $r^{E C B}=0.01$, which are our default values under the unstable scenario (see below), are fixed throughout, but we have performed robustness tests with respect to the values mentioned in the table. 


\subsection{Baseline Scenario}

After running the stable benchmark scenario for generating the initial state of the economy, we now vary the policy parameters to generate various unstable economies. This is achieved by increasing the consumers' price sensitivity parameter from $\gamma=12$ to $\gamma=18.5$, that is, by increasing the competitive pressure on the firms which will reduce their profit margins.

In the baseline scenario both CAR and RRR constraints are weak, using the following parameter settings: $\alpha=8$, that is, the banks' core capital should be at least 12.5 percent of total risk-weighted assets, and $\beta=0.10$, that is, there is a 10 percent central bank reserve requirement.

Scenario description Figure 3 shows the correlation between the business cycle and the financial cycle in the model. The figure illustrates the classic Minskian mechanism of a risky boom, i.e. during the upswing of the business cycle leverage and financial fragility increases, while during a downturn the opposite occurs (Minsky, 1978, 1986). This also corresponds to the mechanism identified by Geanakoplos (2009) as the Leverage Cycle, which explains the increase in financial fragility in terms of collateral constraints.

The figure also shows that financial fragility is synchronized with the business cycle. During booms (phase I, II and III) the firm's leverage rate increases, indicated by a decrease in the average equity/asset ratio, showing signs of increased fragility. Recessions (between phases I-II and II-III) are deleveraging, with an increase in the average equity/asset ratio, which indicates an improvement in financial robustness. During the recovery stage (phase II) the financial fragility increases again, only to be followed by another fragile boom phase. In general, not all boom phases need to be fragile and associated with increased leverage. Similarly, not all recessions need to be deleveraging. Note that at the end of the boom phase I, at the turning point, the average equity/asset-ratio continues to decrease for a while. This is also the case after the second boom phase II, and is most likely due to a debt overhang which causes the financial fragility to have some inertia.

\section{[ADD FIGURE 3: "Mechanism of Financial Instability Hypothesis" ABOUT HERE]}

To uncover the main mechanisms that are underlying this macroscopic result, we illustrate in Figures 4 and 5 the microeconomic situation (or meso-economic, since the plots show sector averaged variables). We show plots for selected variables of the real sector and the banking sector: output, bank activity (number of active units), firm activity (number of insolvencies and illiquidity bankruptcies, for small and large firms), firm sector total debt (again for small and large firms), bank sector average risk exposure, bank sector average equity, firm fragility (average equity-to-asset ratio), and the mean interest rate charged on all new loans per month.

[ADD FIGURE 4: "Baseline Scenario - Financial variables" ABOUT HERE]

[ADD FIGURE 5: "Baseline Scenario - Real variables" ABOUT HERE]

1. Expansion. We start with equal amounts of large and small firms, defined with respect to the mean capital stock: small (large) firms have a capital stock below (above) the mean capital stock, resp. However, this quickly bifurcates into many small firms and a few large firms (Panel 5e). 
From the start, the large firms have a slightly higher capital stock and a higher utilization rate. Hence, the large firms have higher output per firm (Panel 5a) and invest more to expand their production capacities (Panel 5c). At the same time, due to the high competitive pressure, their profit margins are low and some large firms are also generating negative profits (Panel 5b), so they need debt to finance their investments. The investments per firm are substantially higher than those of small firms, who do not invest that much (Panel 5c).

2. Financial side. How are firms able to finance their investments? Since profits are negative and declining, they need new credit to roll-over the old debt. The financial robustness (measured by the equity-asset ratio) of large firms is always below that of small firms, indicating that they are more fragile (Panel $4 \mathrm{~g}$, black curve). The booms typically display an increased leveraging of the large firms (Panel $4 \mathrm{~g}$, black curve), as they must invest to expand (Panel 4d, period 80-150, and period 200-300).

3. Credit bubble. Along the credit bubble the average rate of debt of large firms is building up much quicker than debt of the small firms (Panel 4c). The financial robustness of firms is pro-cyclical; it decreases during recessions and increases during boom phases (as in Figure 3 , phase I).

4. Capacity utilization in relation to investments. The capacity utilization rate is also procyclical and is leading the business cycle by several months, which corresponds to empirical findings in Stock and Watson (1999). During a recession firms make more use of their existing capital stock rather than investing in new capital goods. The utilization rate reaches its maximum during the boom and already starts to decline well before the downturn occurs (see Panel 5d), making it a good indicator for business cycle turning points. During the boom phase investments are high, but the utilization rate already starts to decline due to a slowdown in output, followed by a decline in investments. This is an indication of over-capacities building up during the boom stage of the cycle. When the boom stage is finally over and the cycle has reached its top, the utilization rate is already at a minimum (around 50 percent), investment declines, and financial robustness is at a minimum, i.e. financial fragility is at maximum (Panel 4g, and Figure 3, between phase I-II).

5. Banks. Due to the non-restrictive capital constraint the banks support sound firms as well as unhealthy firms for a long period of time. This yields a higher level of exposure to default risk during booms since the supply of credit is linked to bank equity and therefore pro-cyclical (Panel 4e). Banks become inactive only gradually (Panel 4b), because the capital requirement is slack (Panel $4 \mathrm{~b}$, the red line indicates the number of banks that become inactive due to the capital constraint). Eventually, the liquidity constraint is binding for some banks because large firms' credit demand increases over time (Panel 4b, the green line indicates the number of banks that become inactive due to the liquidity constraint).

6. As a result of this broad supply of liquidity, a considerable number of large and unsound firms continue to produce and receive roll-over credit to finance their debt, exhibited by an unstable debt bubble (Panel 4d, black line). The number of active firms however remains at an artificially high level, since large firms that are actually insolvent and that should have been credit rationed much sooner (had the constraint been more restrictive) are kept alive almost artificially by the banks (below we identify such unsound firms as Zombie- 
firms à la Caballero et al., 2008). In this case the illiquidities are being caused by a binding liquidity constraint of the bank (Panel 4b, green curve and Panel 4c, period 275).

7. Credit Crunch and Re-bound. At the moment the liquidity constraint becomes active, the new credit to large firms declines (Panel $4 \mathrm{~d}$, black line, $t=200$ ). There is a sudden deleveraging of the large firms, shown by the sudden increase in the average E/A-ratio (Panel 4g, period 200). At the same time, their profits improve (Panel 5b), since investments and hence debts decline (Panel 5c). The large firms can increase their output by increasing their capacity utilization rate instead (Panel 5d).

The debt restructuring does not affect the capital stock, so after the unhealthy firms have successfully written off some of their debt, they come back with the same production capacity and start again to expand. This results in another round of leveraging, a new credit bubble is building up (Panel $4 \mathrm{~d}$, black line, $t=250-300$ ), and this is associated to a decreasing E/A-ratio (Panel 4g). Also profits are steeply declining (Fig. 5 Panel 4b) while investments increase (Panel $5 \mathrm{c}$ ). As a result, there remain many illiquidities of both large and small firms even long after the credit crunch (Panel 4c).

8. Comparison of small and large firms. Throughout the entire episode, the small firms do not expand their production capacity and have constant output. Because of their low rate of investments their capital stock even declines (Panel 5g). On the financial side the small firms have positive or slightly negative profits and their financial robustness is better than that of the large firms.

\subsubsection{Prevention and mitigation policies}

Is the credit crunch scenario illustrated above avoidable by restricting the supply of credit? We study this question using the policy parameter $\beta$ that sets the reserve requirement. For higher values of $\beta$, the banks' excess liquidity decreases, leading to a lower supply of credit and the firms' debt levels should be more moderate. The financial instability due to the Minskian dynamics of increasing leverage should be less pronounced.

A relevant policy question is: Can we prevent the economic collapse by implementing a restrictive liquidity supply policy, such that large and financially unsound firms are allowed to fail, due to an induced credit rationing, before they become too big to fail? Is it prudent to restrict liquidity before a credit crunch occurs?

A second question is whether after a credit crunch has already occurred, does it help to restrict the risk exposure of banks to mitigate any damaging effects? One of the origins of the credit crunch is the unwillingness of banks to lend due to their own deteriorated equity levels. A solution of monetary policy is then to reduce the base interest rate of the Central Bank and allow banks to obtain reserves more cheaply from the Central Bank, which they can then use to lend on to firms.

However, since banks in this scenario do not have a liquidity problem but rather an equity problem, pumping more liquidity into the system will not work, since banks are inclined to use that extra liquidity to improve their own balance sheets. This can be related to the notion of balance sheet recessions, that is, recessions driven by debt deleveraging leading to a prolonged slump (Koo, 2009, 2010). Instead of passing it on to firms in the form of loans, banks can use the additional reserves to purchase government bonds, or invest in firm equity, or other financial assets, in order to receive the capital gains and dividends from such investments. It is to be expected that the additional liquidity provided to the banking sector in a quantitative easing policy will not lead to inflation of the consumer prices, but will in all likelihood lead to asset 
price inflation, i.e. an asset bubble. There is ample empirical evidence in support of this claim, for example the Japanese stock market bubble in 1987-1990, and the more recent experiences with the U.S. stock market bubble in 2010, and the EU stock market bubble in January 2015. Each of these episodes was preceded by very low discount rates, and banks using the excess reserves to invest in high-yield assets, what we earlier referred to as a 'flight to quantity'.

In other words, a monetary policy aimed at fixing the credit crunch after it has occurred by flooding the market with liquidity is not likely to work since it goes against the incentives of the bank. Instead, what could be done to prevent a credit crunch is to restrict the level of default risk and thereby to prevent banks from entering into the situation of having low equity levels in the first place.

Such a monetary policy could be steered by the capital adequacy ratio. Therefore we proceed by demonstrating the effect of a more restrictive capital constraint, and investigate whether this helps in restraining the banks sufficiently in order to prevent unhealthy firms from growing too large that they pose a systemic risk to the entire banking system.

\subsection{Policy analysis}

In this subsection we examine how a tightening of the Capital Adequacy Requirement (CAR) respectively the Reserve Requirement Ratio (RRR) affects the economic dynamics. We follow the empirical literature on the relationship between financial cycles and business cycles (c.f. Claessens et al., 2011; Jordà et al., 2011; Schularick and Taylor, 2012) to select the relevant indicators for measuring a positive policy effect (see Appendix B for details). In particular, we consider the amplitude and cumulative loss of output during recessions as an indicator of the economic loss associated to severe downturns. The amplitude of a recession is measured in units of output, from the top of the boom phase to the through of the downturn. The cumulative loss is measured as the output that is not being produced during the entire duration of the recession, by combining the amplitude and the duration measure. In line with our main motivation for this study we are especially interested in the effects of the different policies on the lower part of the distribution of these measures, i.e. on the severity and probability of the most extreme downturns.

\subsubsection{Tightening the capital adequacy requirement}

In Figure 6 we report results for the amplitude of recessions, under different scenarios with respect to the CAR. The box plots show the distribution of all amplitude values for all recessions that occur, pooled across 20 simulation runs (one run contains on average $5-10$ recessions, so the number of observations lies between $100-200$ recessions per box plot).

The considered range for $\alpha$-values is from 1 to 32. The current capital adequacy ratio in Basel II is $\kappa=4$ percent, corresponding to $\alpha=25$. The minimal core capital requirement proposed in Basel III is set at $\kappa=7$ percent, which corresponds to $\alpha \approx 14$, whereas the value $\kappa=10.5$ percent $(\alpha \approx 9)$ holds if all regulatory requirements including the discretionary counter-cyclical capital buffers for SIFIs are taken into account.

The box plots in Figure 6 show that for the maximal value of $\alpha=32$ (3 percent regulatory capital) the bottom whisker indicates that 95 percent of recessions have amplitudes between 0 and -1900 units of output lost. A more restrictive CAR implies lower values of $\alpha$ and this corresponds to an increase in the amplitude of recessions, at least until one reaches $\alpha=4$, which corresponds to a capital adequacy ratio of $\kappa=25$ percent and is still within the range proposed by Admati and Hellwig (2013). The extremely low values of $\alpha=1$ and $\alpha=2$ correspond to $\kappa=100$ percent and $\kappa=50$ percent resp., which are theoretically feasible, but implausible 
values in practice. A capital adequacy ratio of 100 percent would surely make the economy very stable and reduce the amplitude of severe downturns, which is also seen in the box plots, but this level is politically unattainable.

\section{[ADD FIGURE 6: "Boxplots Capital Adequacy Requirement" ABOUT HERE]}

To understand in more detail the mechanisms underlying this observation we consider the dynamics in a scenario with a very restrictive CAR, namely $\alpha=2.0(\kappa=50$ percent $)$ and $\beta=0.10$. We emphasize that is not meant to be a realistic value, but is used to clearly illustrate the dynamics at work. This scenario shows exactly what happens during a credit crunch when all banks stop lending. The main driving mechanism behind the economic collapse is the slow build-up of debt in unhealthy firms that increases the risk exposure of banks. A strict capital constraint causes a sudden collapse, instead of a more gradual deleveraging of debt. This sudden collapse then gets transmitted to the real sector. In Figure 7 we illustrate the main mechanisms underlying such effects of a tight CAR constraint.

\section{[ADD FIGURE 7: "Scenario Capital Adequacy Requirement" ABOUT HERE]}

1. Build-up. The non-binding, weak liquidity constraint has flushed the credit market with liquidity, so that total credit develops into a bubble (Panel d). At the start many firms are increasing their debt to finance production and financial commitments. As in the baseline scenario, the large firms have large liquidity needs, so they cause the banks to build up large risk exposures (Panel e). But since in this scenario the CAR constraint is more strict, they hit it more often. This tougher constraint shields a small number of banks from becoming insolvent, although they do become inactive due to a binding CAR (Panel b). They can become active again later on.

2. Credit Crunch. Once banks have stopped lending, the deposits in these banks are no longer available on the RHS of the RRR constraint, which makes them "unproductive". If other banks would hold these deposits they could expand the liquidity supply by leveraging up their reserves. So in this respect, the reserves in the inactive banks are unproductive.

This affects the unhealthy firms the most since they have lower E/A-ratios (higher D/E ratios) which puts them at the bottom of the risk-ranking in the banks. Hence, the large firms are more likely to be credit rationed and the number of illiquid large firms increases in comparison to the baseline scenario. However, also the small firms are harmed due to the consequent credit crunch (Panel c).

3. Insolvency of bad firms. The economic breakdown occurs in two stages. The first stage is characterized by unhealthy (Ponzi) firms becoming insolvent (Panel c, black and red curves indicate insolvent firms). The insolvencies of bad firms are not harmful in the beginning, but as bad firms have higher debt, they will default on larger loans as well, affecting the banks' balance sheets through the equity channel (the narrow bank lending channel).

4. Bank equity. The continued insolvencies of these firms causes a slow deterioration of bank equity (Panel f). This affects the banks' ability to provide new loans, as the budget for risk exposure is diminished. The more restrictive CAR implies that the turning point in the bank equity bubble comes earlier, hence the credit crunch starts earlier. 
5. Active capital constraint. When the equity of a majority of banks has eroded sufficiently, the capital constraint becomes active. The plot of bank activity (Panel b) illustrates well that the first constraint to become binding is the capital constraint (the red line indicates the number of banks that have become inactive due to a binding CAR constraint). Note that the total number of inactive banks includes banks that are insolvent, as well as banks that have either the CAR or RRR constraint binding. At the same time, a small number of banks stop lending due to negative equity and the first wave of illiquid firms ensues around period 180 (Panel c).

6. Credit crunch. In the second stage it is the re-financing of debt by the Ponzi firms that are not yet insolvent but that require liquidity to keep them afloat which is going to bring about a collapse in output (Panel a, period 325). First, the disappearance of bad firms reduces total output since they go out of business.

7. Large firms rescale production. Second, the bad firms that do remain in business cannot get any credit for production or to service debt. Since priority is given to debt servicing, they must rescale production. Thus, the collapse in output is the combination of a production stop by the inactive firms and the reduction in output by the active firms (Panel a, period $325)$.

8. Bad firm illiquidity. There is a large number of synchronous illiquidities of bad firms, since the bank gives priority to healthy firms and rations the credit to unhealthy firms (Panel c). This could be either small (S) or large (L) firms. What happens to these illiquid firms? During the bankruptcy procedure these firms are restructuring their debt, so they return (after 12 months) as healthy firms in the population. However, as soon as the capital constraint of the bank ceases to be restrictive (i.e, the bank's risk exposure is reduced due to the debt restructuring of the illiquid firms) the number of Ponzi financed firms starts to increase again and another debt bubble is formed (Panel a, around period 250-300).

9. Banks inactive. This causes further damage to the bank balance sheets and as soon as equity is negative or the maximum exposure limit is reached the bank stops providing loans to firms all together. This reduces many banks to the inactive status (Panel b, period 325) due to negative net worth (Panel f, period 325) and results in an overall credit crunch (Panel c, period 325). The banks' excess liquidity is still positive, so the banks could lend from a liquidity point of view, but their regulatory core capital does not allow it.

10. Restarting the credit bubble. Because there is no restriction on liquidity, the debt bubble will restart after the capital constraint has relaxed again (Panel d, after period 400).

It is important to note that the liquidity constraint (RRR) in this case hardly ever becomes binding, as the value of $\beta$ is too low. This can be verified in (Panel $b$, green curve) which indicates the number of banks that become inactive due to a binding liquidity constraint. Note that at the moment of the credit crunch, around period 250, the number of illiquid large firms is higher than the number of illiquid small firms, which is an indication of an indirect contagion effect through the banking system which we could call the Zombie-effect (see Caballero et al., 2008). The Zombie-effect is the notion that a small number of unhealthy firms with a high risk profile hamper the ability of banks to provide liquidity to other, more healthy firms. After the unhealthy firms have been allowed to grow and subsequently become insolvent and write off their debt, the banks' equity is depressed to such a degree that they cannot supply any credit to any other firms. It is therefore in the interest of these banks to keep the bad firms alive as long 
as possible, hence the name Zombie-firms. In addition, there continue to be firm illiquidities (Panel c) for a long period of time after the sudden wave of illiquidities. Another important effect is the large concentration in the banking sector (Panel b, after period 325 only 2 or 3 banks remain active).

\section{Network analysis}

Figure ?? shows this effect in terms of the time-evolution of the network of credit relationships between banks and firms. Shown are snapshots of the network, at $t=-300,500,900$ and 1,000 months. The initial state at $t=-300$ (before the burn-in state) is such that each firm $(n=80)$ has a single loan with a randomly assigned bank $(b=20)$. After some time a core-periphery network appears endogenously, with some banks in the centre of the network having many credit links, while other banks that are on the periphery have far fewer links. The endogenous link formation process can be described as follows:

1. At $t=500$ : the network is fully developed, with 10 banks in the core, with each bank having more than 10 links (the largest connected component), 5 banks in the periphery with 1-9 links, and 5 banks are completely disconnected.

2. At $t=900$ : the network starts to break down as the financial contagion effect produces a concentration in the banking sector.

3. At $t=1,000$ : the breakdown is more clearly visible with only 4 banks remaining in the core, 6 banks in the periphery, and the remaining 10 banks that are completely disconnected without any credit relationships.

\section{[ADD FIGURE ??: "Networks" ABOUT HERE]}

\section{The (dis)advantage of strict capital policies}

After having seen these results, we might ask: Is there any advantage to having a strict capital adequacy requirement? Risky firms are restricted from obtaining large debts, so that as the debt bubble breaks banks are less affected. The sudden effectiveness of the capital constraint causes more banks to survive, but it does not prevent the surge of firm illiquidities that follow the credit crunch.

The disadvantage of a strict capital policy is that after the CAR constraint is no longer binding, the surviving banks have high liquid resources that are now used to start another credit bubble. Since there has been a wash-out of the competition and a concentration in the banking system the remaining banks now gain more profits and can maintain the credit bubble for longer. The bad firms can again obtain financing, output recovers quickly, but in the meantime the average debt of bad firms is building up to greater heights than during the original bubble.

In conclusion, a more stringent CAR constraint does not solve the underlying problem that banks are running up their risk exposure and that financially unsound firms are receiving too much credit. To solve this, a combination of the capital adequacy ratio and the liquidity constraint seems needed.

In the next scenario the restrictive capital constraint is replaced by a restrictive liquidity constraint. Instead of breaking the credit bubble the intent is now to prevent the bubble from growing in the first place. 


\subsubsection{Tightening the reserve requirement}

In Figure 8 we report results for the amplitude of recessions, under different scenarios with respect to the $\mathrm{RRR}$ constraint (varying the parameter $\beta$ ). As above, the box plots show the distribution of all amplitude values for all recessions that occur, pooled across 20 simulation runs. The considered values of $\beta$ span the entire range from 0 to 100 percent reserve requirement, and a more restrictive RRR corresponds to higher $\beta$-values. For the $\alpha$-value we have considered here the most restrictive case of Basel III, namely $\alpha=9.5(\kappa=10.5$ percent $)$. From the box plots it becomes clear that a more restrictive RRR is associated to a decrease in the amplitude of recessions.

The generic robustness of this result is illustrated by Figure 9, which shows a two-dimensional parameter sensitivity analysis for a 10-by-10 grid of parameter values $\alpha=4, \ldots, 32$ and $\beta=$ $0, \ldots, 1.0$. Each grid cell contains the value of the lower whisker of the box plot of the amplitude of recessions (across 20 runs). The generic result is that a tighter Reserve Requirement Ratio of 50 percent works much better to contain the severe downturns than a tighter CAR constraint.

[ADD FIGURE 8: "Boxplots Reserve Requirement Ratio" ABOUT HERE]

[ADD FIGURE 9: "Two-dimensional parameter sensitivity plot" ABOUT HERE]

To explore this scenario in more detail we consider the dynamics under the parameter setting $\alpha=8$ and $\beta=0.5$, corresponding to a restrictive 50 percent reserve requirement but a nonrestrictive capital adequacy ratio of 12.5 percent. Figure 10 illustrates the main mechanisms for this scenario.

\section{[ADD FIGURE 10: " Scenario Reserve Requirement" ABOUT HERE]}

1. Liquidity constraint binding. The bank gives credit up to its constraint which then becomes binding (Panel b, green curve). As the liquidity constraint is binding, the capital constraint is not binding (Panel b, red curve). In case a bank is illiquid it draws advances from the Central Bank and remains active. This means banks with a binding liquidity constraint all remain active and equity remains positive. Since the credit demand of large unsound firms is typically larger than that of small firms - the replacement investments are typically larger when the firm has a larger capital stock, and total debt is larger in order to finance the investments - the former are more often credit rationed than the latter. This causes large firms to enter into illiquidity bankruptcy at an earlier stage and not all simultaneously (Panel c, blue curve).

2. Waves of illiquidity instead of one big surge of illiquid firms. Because the liquidity constraint remains binding, large firms are becoming insolvent and illiquid during the entire second half of the simulation (Panel c, black and blue curves). The bad debt is spread out over time and does not harm the banking sector that much, allowing it to be absorbed by the banking system and banks become inactive more gradually. (Panel b, black curve).

3. A Schumpeterian Cleansing Effect. The banks continue to provide loans, hence after the wash-out of the financially unsound large firms that became illiquid (Panel c, periods 200 and 300), a new credit bubble is formed and total credit to firms is increasing again (Panel d, red line,periods 225, 325). This could be attributed to a so called cleansing effect of Schumpeterian firm evolution, in which the bad firms are bankrupted in favour of the more healthy surviving firms. 
4. Total bank exposure (Panel e) is lower in the case of the restrictive liquidity constraint exactly due to the absence of a credit crunch. Moreover, this total exposure is distributed among many more banks hence the banking system as a whole is more robust against the failure of a single, large firm.

\section{Advantage of the non-restrictive reserve requirement}

If there is no restraint on lending this encourages over-leveraging by the banks, the supply of new loans is high, and the bank takes on more risk. The possibility to refinance old debt causes firm indebtedness to rise, even if profits are decreasing, so this encourages over-leveraging by firms. Financial fragility is expected to increase.

The weak liquidity constraint allows the credit bubble to form until it breaks due to the capital constraint. In this case there is no bail-out of banks, no recapitalization, so the banks suffer and a credit crunch follows in which banks suddenly refuse to lend. This could lead to many simultaneous firm illiquidities.

The restrictive liquidity constraint does not allow a credit bubble to form in the first place. It is pre-emptively cutting the bubble off and forces a deleveraging of debt. There is a higher likelihood of banks staying alive since the lower exposure to fragile firms causes smaller bad debt when they go bankrupt, hence less harm is done to the banking system. Also, the risk of synchronous firm failures is smaller.

A fully accommodating monetary policy by the central bank implies it will step in to provide liquidity to failing banks automatically through the standing facility or discount window. This saves the banks, preventing a bank collapse and they continue to lend to all firms, financially sound or unsound. They also continue new credit to large firms to roll-over larger debts. The number of supported unsound firms remains high, and bad debt remains high as well. But the collapse in output seen in the baseline scenario is prevented.

In general, the illiquidities of healthy firms have been replaced by their insolvencies. This is a good feature, in the sense that the illiquidities signalled an inefficient allocation of credit that resulted in a "congestion"-effect in the credit market. In the scenario with restrictive reserve requirement, the insolvencies indicate that banks are letting unhealthy firms exit the market instead of supporting them and crowding out the smaller, healthier firms.

Another advantage is that the higher reserve requirement bolsters banks' equity. The relatively high number of bad firms that can be sustained in such a case due to the banks' robustness leads to a lower exposure to credit risk. Moreover, this risk exposure is distributed among many banks, reducing the risk that a single bank failure causes a sudden wave of simultaneous firm illiquidities, which would again affect the banking system. The banks are robust enough to cope with the negative effects of supporting the financially unsound firms, while at the same time allowing a moderate number of unsound firms to fail. This allows them to support more of the financially healthy firms, and to prevent the "congestion"-effect on the credit market.

\section{Discussion}

In this paper we have considered the leverage cycle as the main transmission channel of risk between firms and banks. The traditional transmission channel of monetary policy is through the credit channel, i.e. the broad and narrow channels, that refer to changes in the value of assets on the balance sheets of borrowers and lenders, respectively. This dichotomy however overlooks the important role of collateral constraints, which bind the two channels together. 
Our analysis shows that a liquidity constraint that prevents banks from fueling a debt bubble, that is mainly caused by the financially unsound firms requiring new debt to roll-over old debt, is of crucial importance for the banks' survival. Hence, such a constraint is highly effective in avoiding deep downturns of the economy.

A capital adequacy requirement is insufficient to ensure the viability of the banks, since without the liquidity constraint the banks might continue to finance certain bad firms and a debt bubble will (re-)appear. Sooner or later these bad firms will become insolvent. When this occurs the bad debt will affect the banks' equity, and so reduces the supply of liquidity.

If there is a liquidity constraint in place, the unsound firms are credit constrained first, before they become insolvent, and this causes them to enter into early illiquidity bankruptcy, without the banks' equity being affected too much to cause serious damage to the banking sector. By cutting-off the provision of credit to the unsound firms they are also prevented from building up large debts, hence the total bad debt is lower. A debt bubble and subsequent credit crunch does not appear, allowing banks to absorb the moderate write-off's on their balance sheets.

Concerning the effect of different types of credit market regulations on macroeconomic performance, we have four main results wrt. to the amplitude of severe downturns: (i) a more restrictive capital adequacy ratio corresponds to an increase in the amplitude of recessions; (ii) a more restrictive reserve requirement ratio corresponds to an decrease in the amplitude of recessions; (iii) a very tight reserve requirement ratio of 50 percent or more generically works better to dampen severe downturns than any level of restrictive capital adequacy ratios; and (iv) due to the restrictive liquidity constraint, the illiquidities of healthy firms have been replaced by their insolvency, preventing a "congestion"-effect from occurring on the credit market.

Many avenues for further research on the relationship between firms' financial fragility and banks' systemic risk remain. Next on our research agenda is the analysis of the endogenous network dynamics. For example, one could study the network of banks just before a crisis occurs, and compare that network structure to the empirical bank network data. We have hinted at this in the main text, where we show that the number of banks that remain active is gradually declining in the system, hence the financial contagion causes a concentration effect in the banking sector. One could also consider the time-evolution of an empirical bank-firm network, with or without considering crisis periods, and then compare the empirical network dynamics to the network dynamics in the model.

Currently, our model contains only one dynamic network structure that is formed endogenously: the firm-bank network of credit relationships. This could easily be extended to include: (a) an interbank market with bank-to-bank credit relationships; (b) a model with trade-credit with firm-to-firm credit linkages; (c) an extension for explicitly addressing macro-prudential policy issues; (d) stress-testing of individual banks, or of the network as a whole, by tracking the domino-effects of financial contagion, see, e.g., Battiston et al. (2012) for work in this direction. 
Table 4: List of parameters.

\begin{tabular}{lll}
\hline Symbol & Name & Value \\
\hline \hline$\underline{\text { Agents }}$ & Households & \\
& Consumption goods producers & 1600 \\
& Investment goods producers & 80 \\
& Banks & 1 \\
& Central Bank & 20 \\
& Government & 1 \\
& & 1 \\
Consumption goods & Price sensitivity & \\
$\gamma$ & Income tax rate & 18.5 \\
$\tau$ & & $0.05(5 \%)$ \\
Credit market & Debt repayment period & $18 \mathrm{months}$ \\
$T^{\text {Loan }}$ & ECB base interest rate & $0.01(1 \%)$ \\
$r^{E C B}$ & Deposit interest rate & $0.009(0.9 \%)$ \\
$r^{d}$ & Bank's interest rate multiplier & 3 \\
$\lambda^{B}$ & Debt rescaling & $0.30(30 \%)$ \\
$\varphi$ & & \\
Financial market & Capital Adequacy Requirement & $8(12.5 \%)$ \\
$\beta$ & Reserve Requirement & $0.10(10 \%)$ \\
$d$ & Dividend ratio & $0.70(70 \%)$ \\
$n_{R}$ & Months of revenues in dividend rule & 6 \\
$n_{E}$ & Months of net earnings in dividend rule & 4 \\
$\mu$ & Threshold in dividend rule & 0.5 \\
\hline & &
\end{tabular}




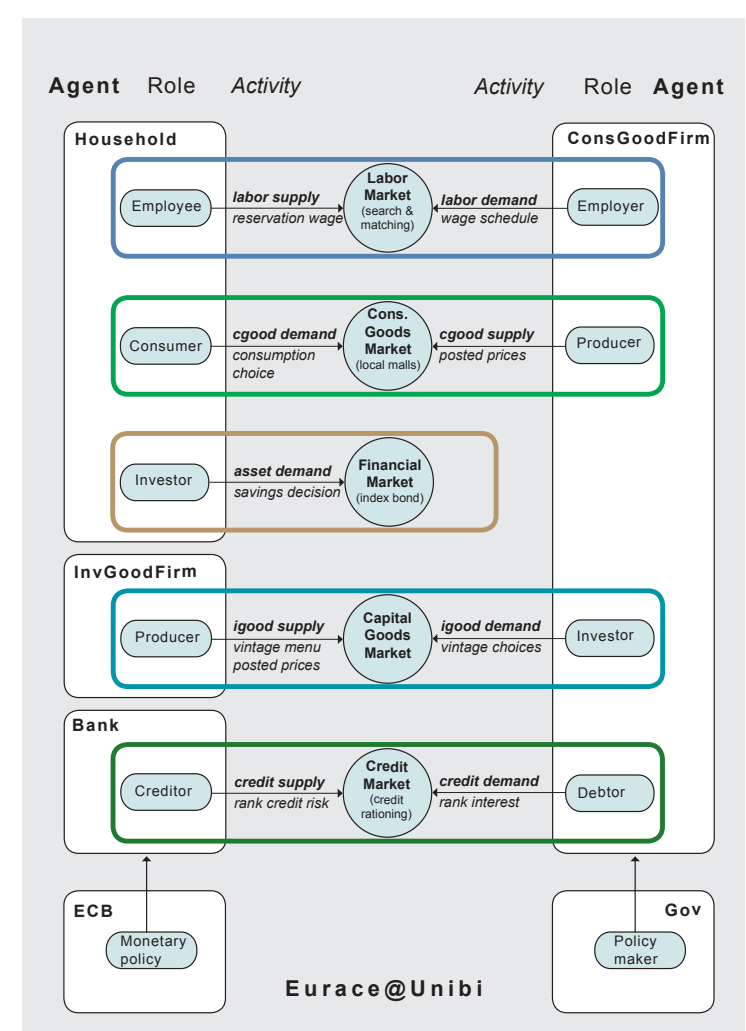

Figure 1: Overview of the Eurace@Unibi model.
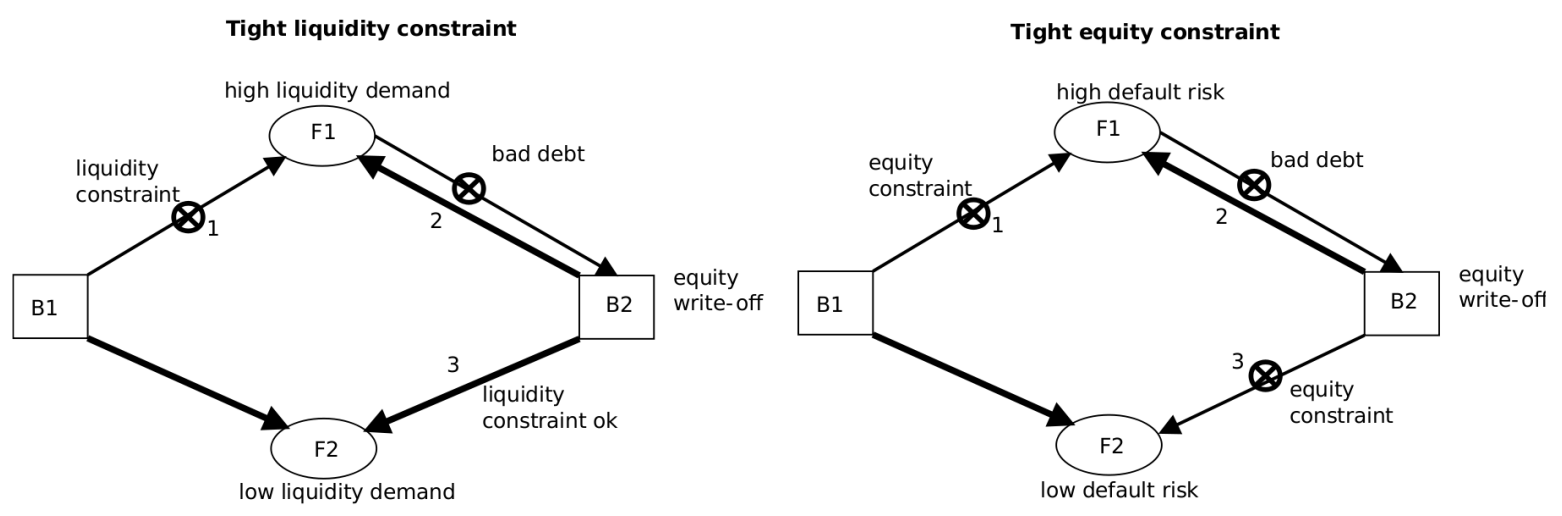

Figure 2: Liquidity and equity channels of financial contagion. 


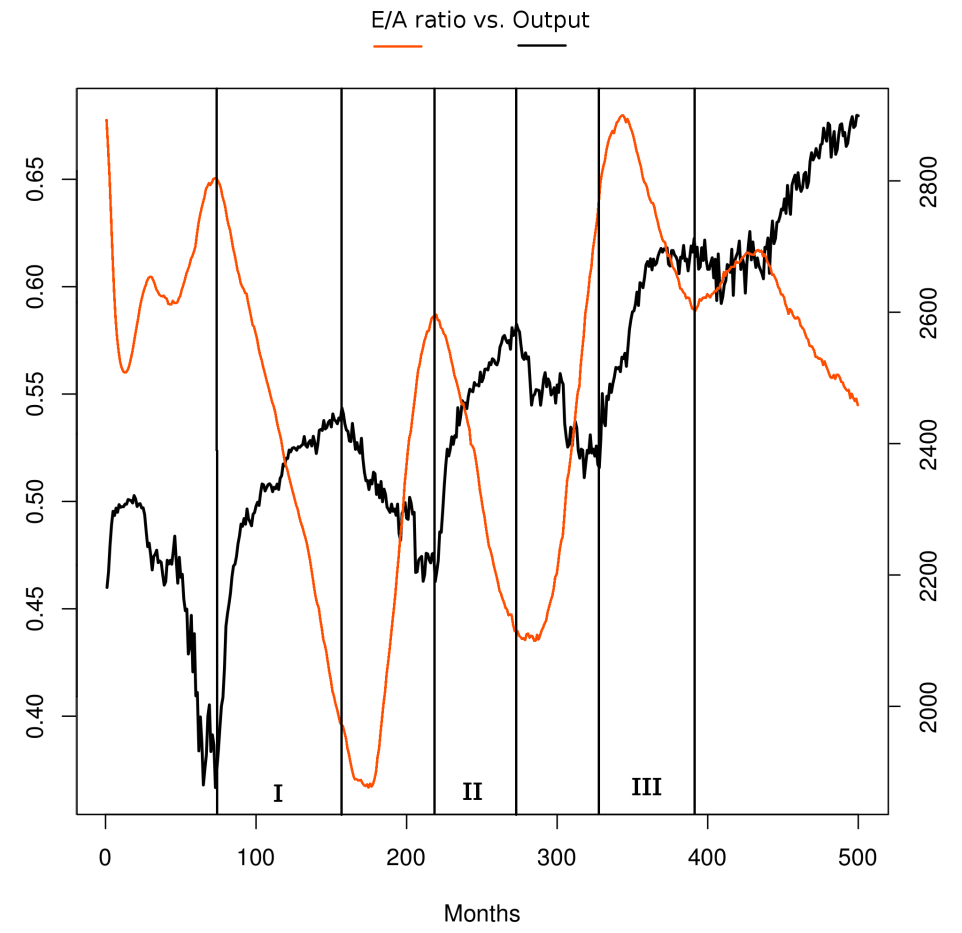

Figure 3: Mechanism of the Financial Instability Hypothesis. Parameters: $\alpha=8, \beta=0.50$, $\gamma=20$. 

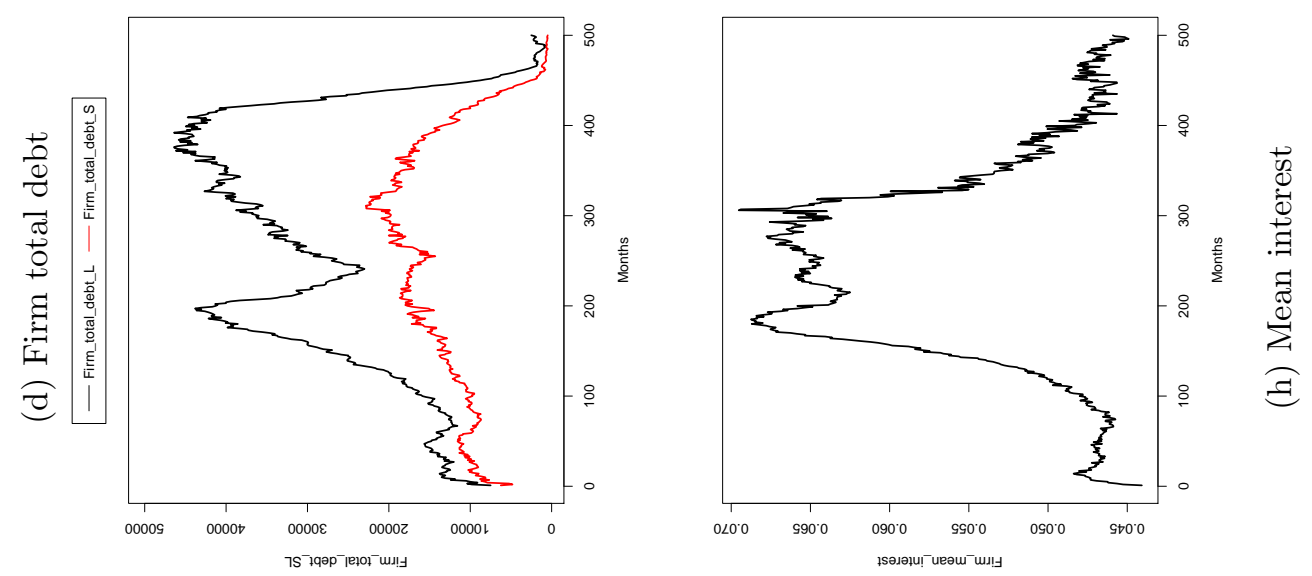

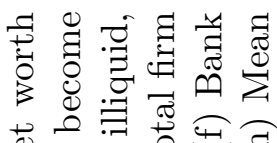

䒕

.

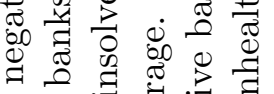

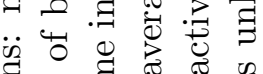

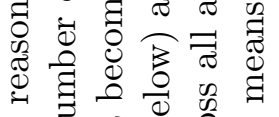

\&

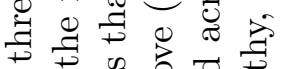
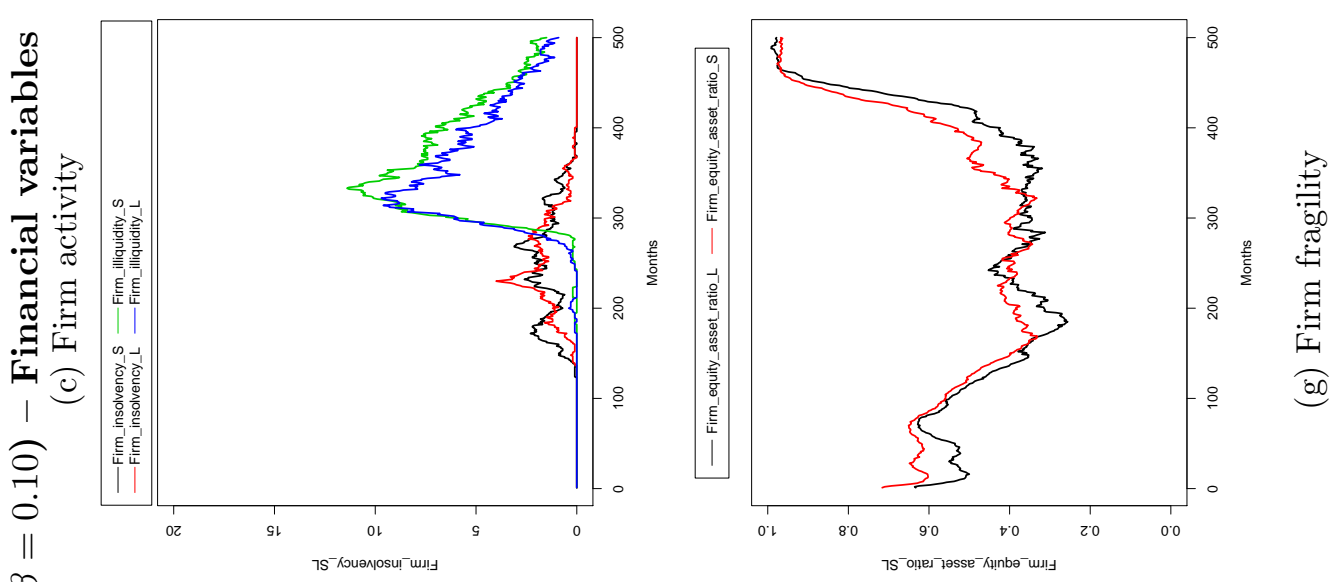

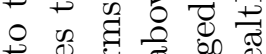
政 उ. :

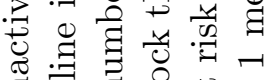
.

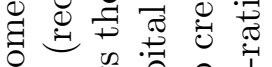
षี

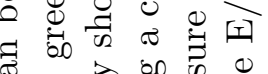
đ

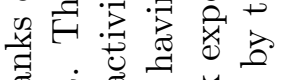

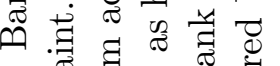
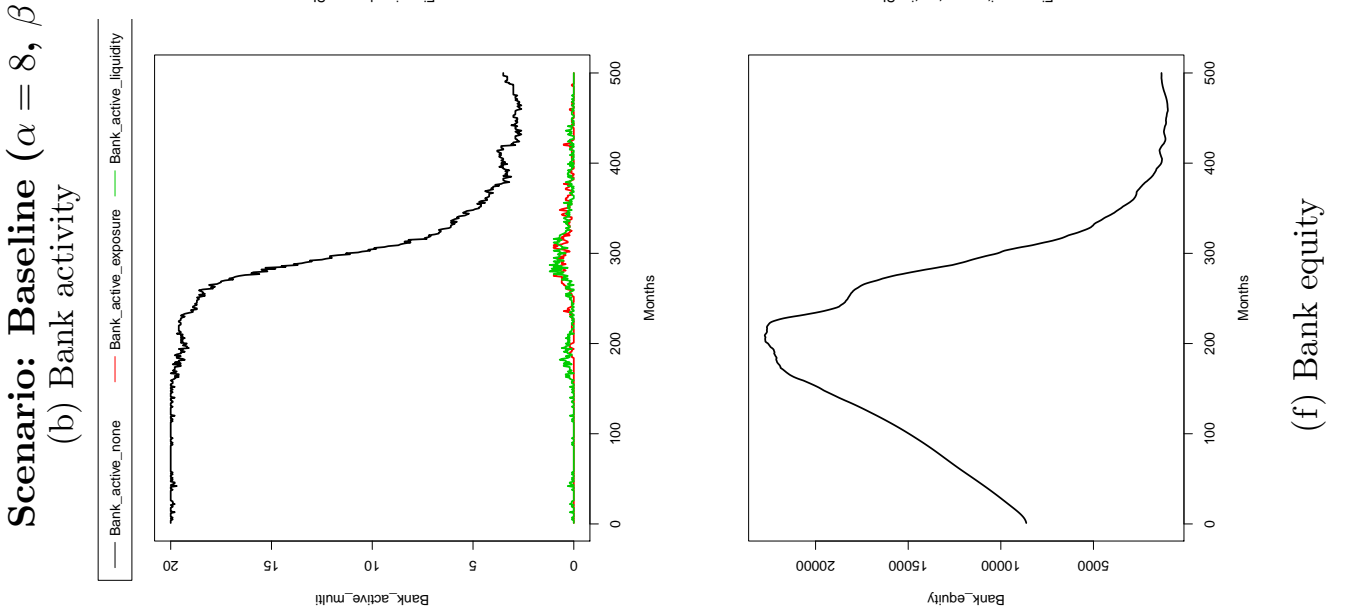

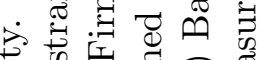

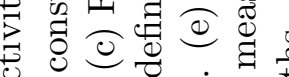
平完范 艺 范 คึ อิ

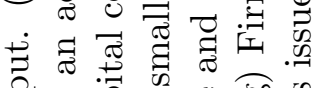

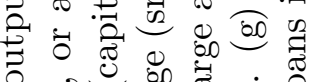

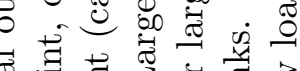

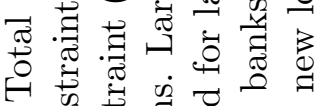

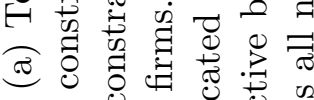
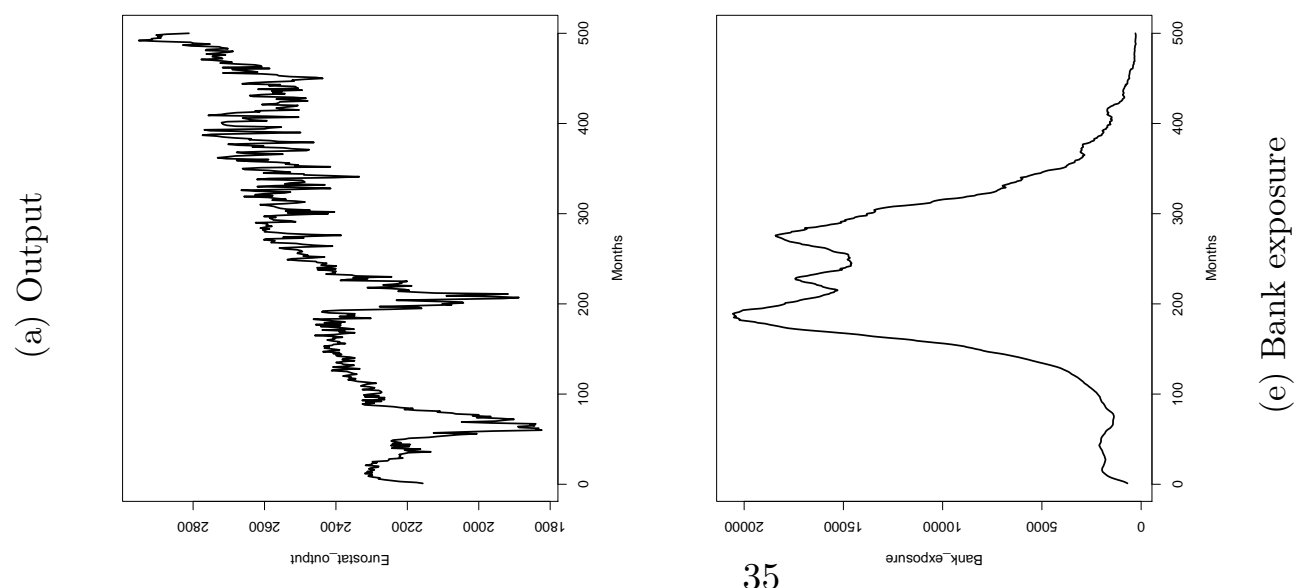

م 0.0

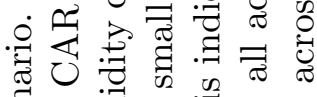
ఫ. n 园 คิ $\ddot{4} \circlearrowright$

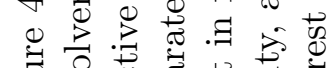

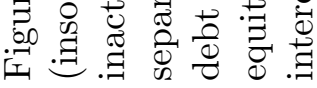




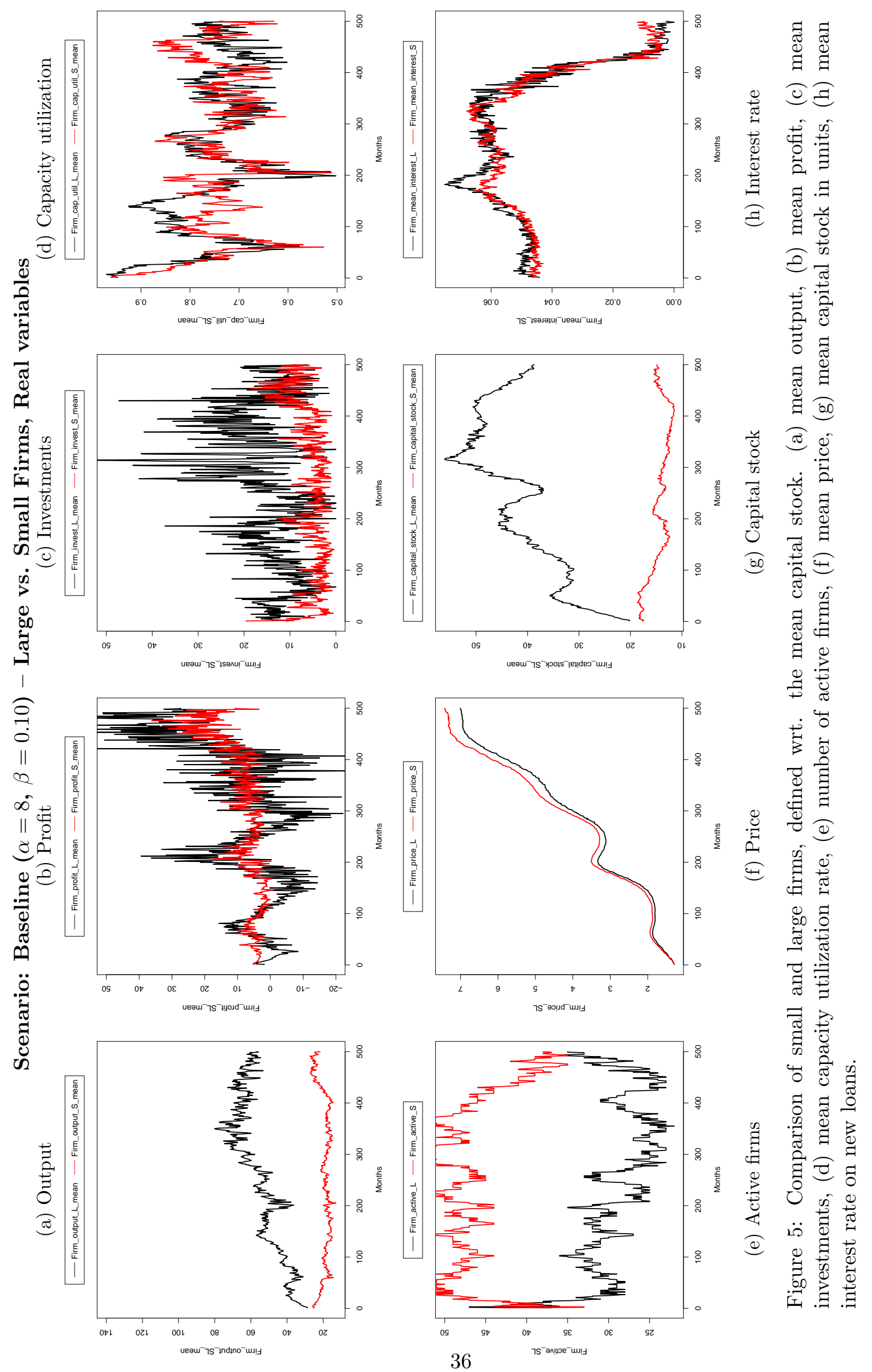




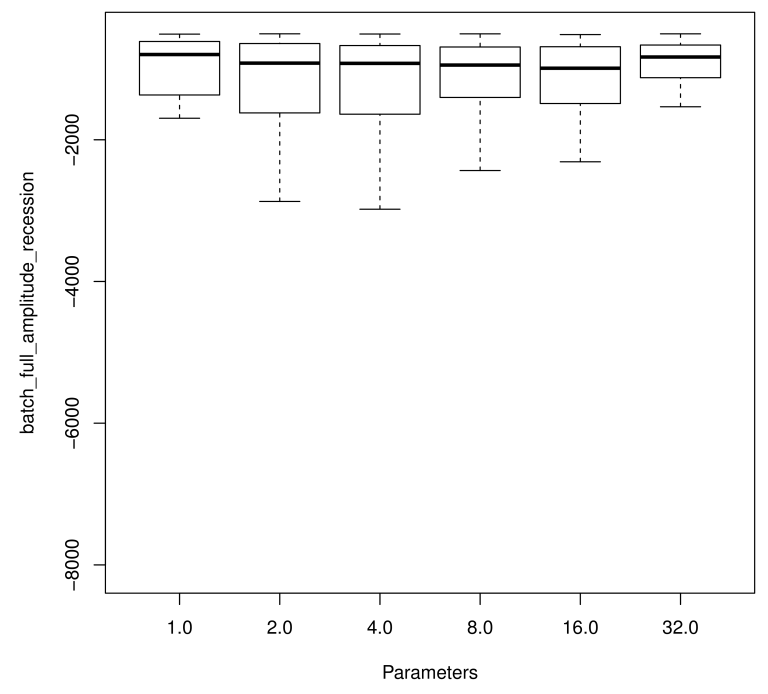

Figure 6: Boxplots of the amplitude of recessions for different values of $\alpha$ and $\beta=0.10$. Parameter sensitivity analysis wrt. the $\alpha$-parameter related to the Capital Adequacy Requirement (CAR). A more restrictive CAR (lower $\alpha$-values) corresponds to the an increase in the amplitude of recessions. Amplitude is measured as the total loss in output, from the peak of a boom to the through of the recession. For each parameter value the boxplot shows the distribution of all recessions across 20 batch runs, for simulations of 500 months. 

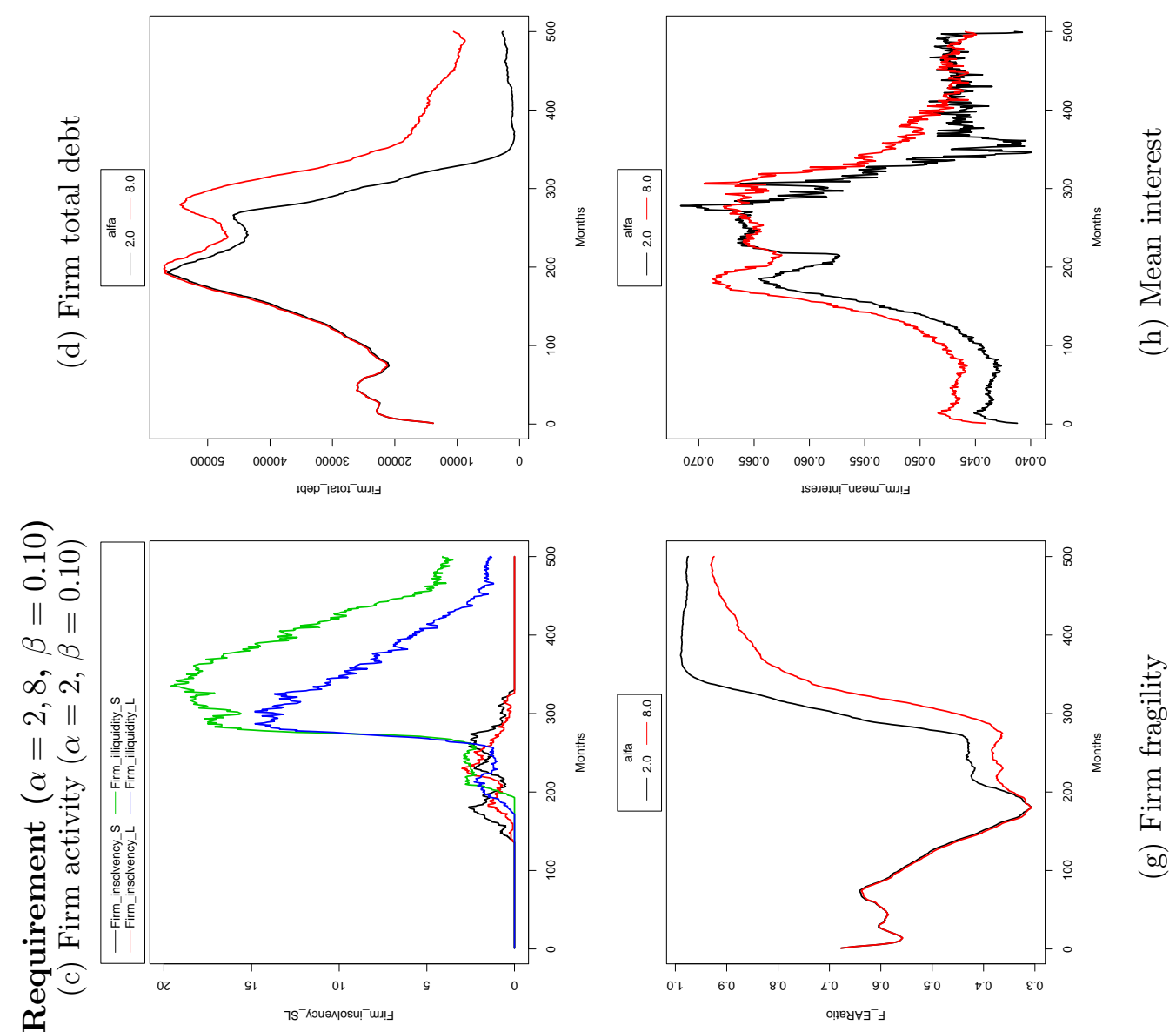

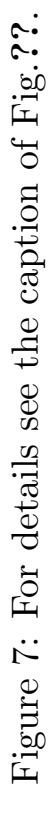
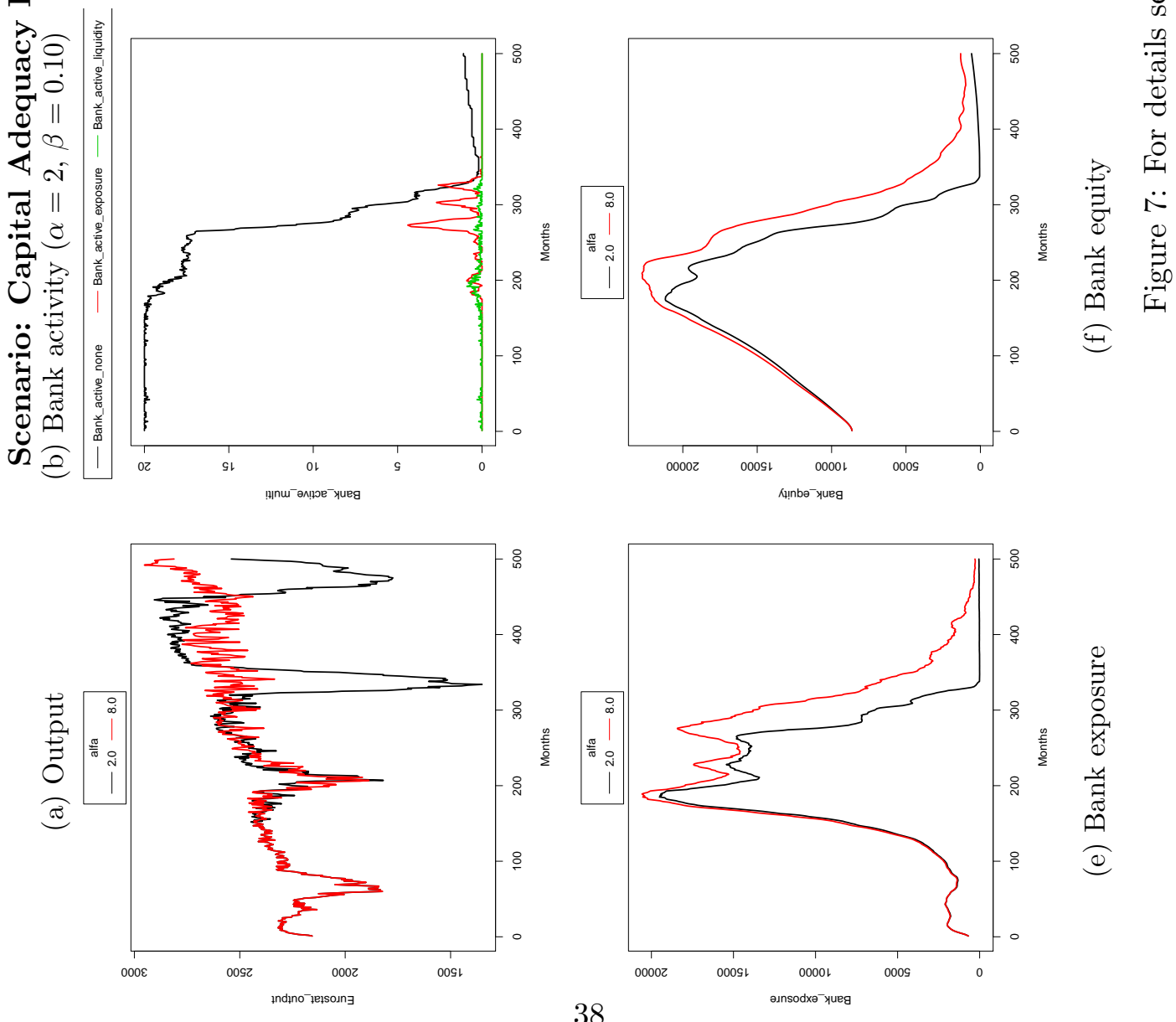


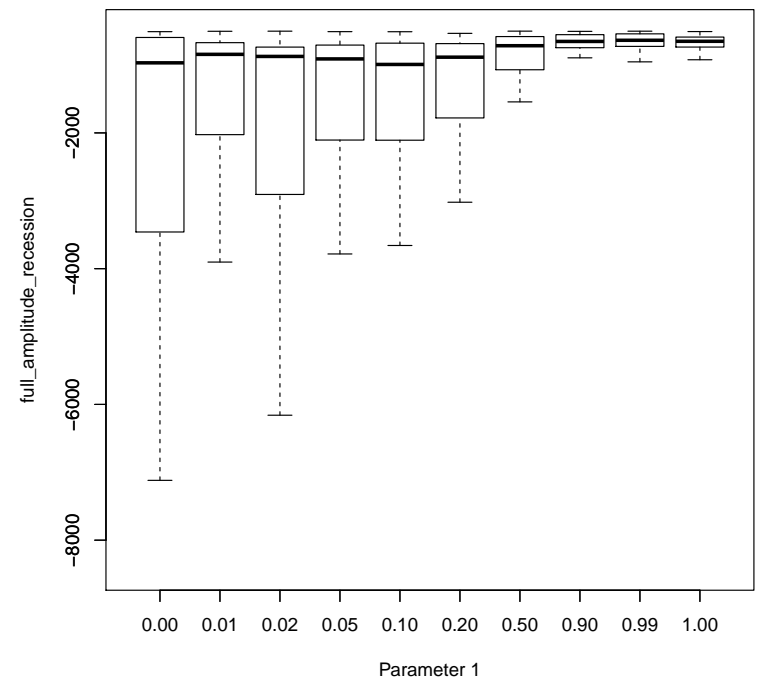

Figure 8: Boxplots of the amplitude of recessions for different values of $\beta$ and $\alpha=9.5$ $(\kappa=10.5 \%)$. A parameter sensitivity analysis wrt. the $\beta$-parameter for the Reserve Requirement Ratio (RRR). A more restrictive RRR (higher $\beta$-values) corresponds to a decrease in the amplitude of recessions. Amplitude is measured as the total loss in output, from the peak of a boom to the through of the recession. For each parameter value the boxplot shows the distribution of all recessions across 20 batch runs, for simulations of 500 months.
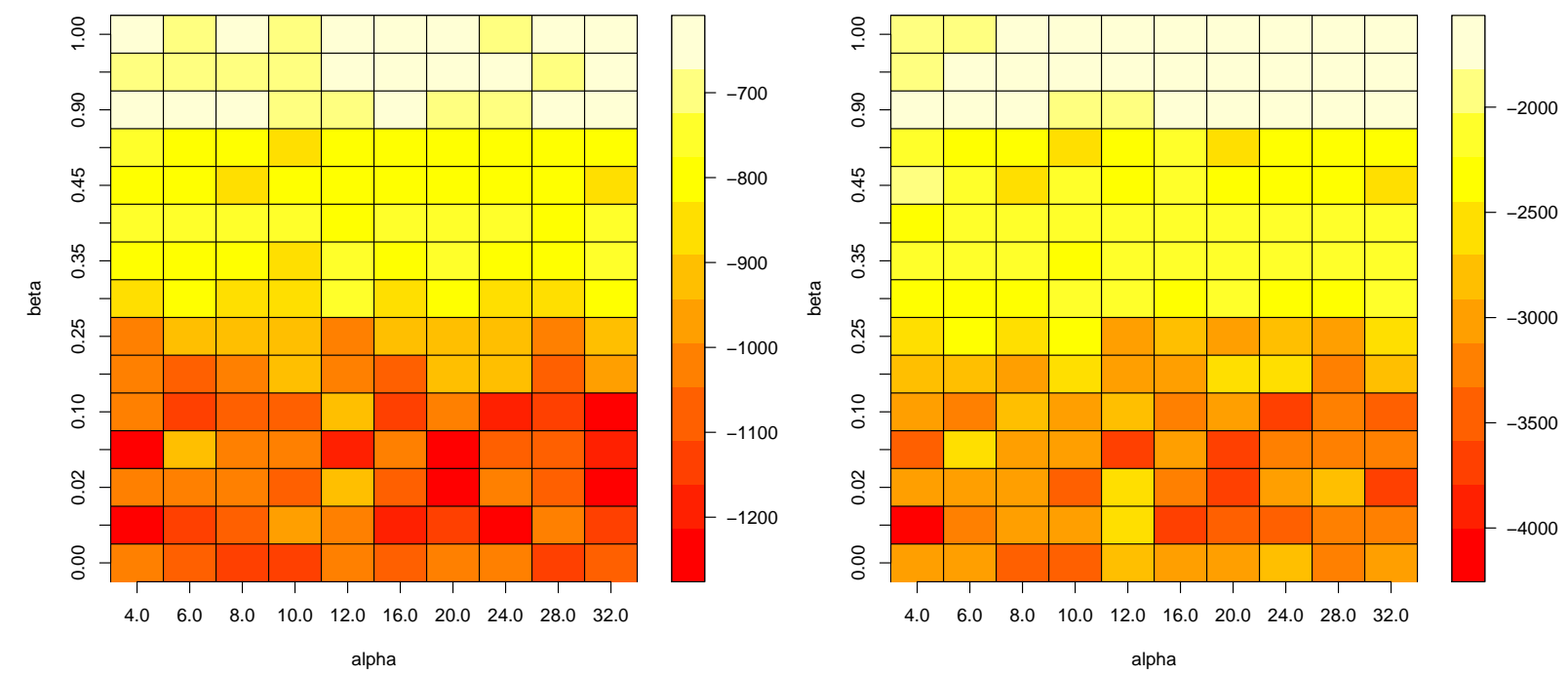

Figure 9: Two-dimensional parameter sensitivity plot for values: $\alpha=4, \ldots, 32$ and $\beta=0, \ldots, 1.0$ $(10 \times 15$-grid, 20 runs per cell). The grid cells contain the value of the lower whisker of the box plot. (a) amplitude of recessions in real terms (units not produced); (b) cummulative loss of recessions in real terms (units not produced across duration). 

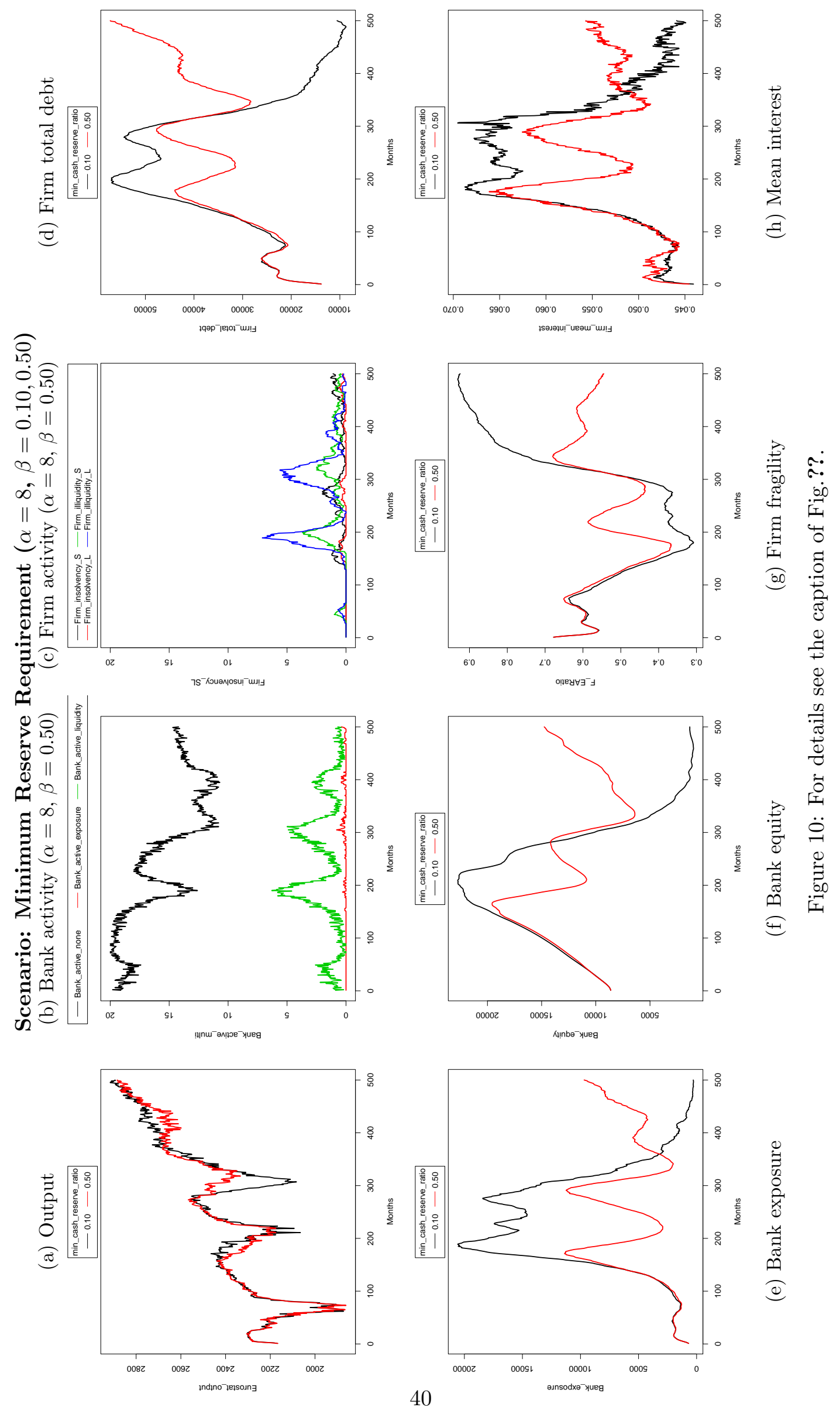


\section{A Note on behavioral assumptions and model consistency}

As in any economic situation, we should distinguish between ex ante and ex post, and take into account the expectations that agents form about the constraints they are facing. Before taking any decision, agents are guided in their behavior by their perceived (anticipated, expected) constraints they belief they are facing. These perceived constraints we may call ex ante constraints. However, the actual constraints that agents in fact face ex post may be less restrictive or more restictive than the agent had anticipated. This distinction between ex ante and ex post constraints will be important in what follows.

We have the following definition on the model consistency of behavioral assumptions:

Definition 1 A behavioral assumption is called model consistent if the ex ante, perceived constraint coincides with the ex post, actual constraint.

In our modelling of the risk-taking behavior of the banks (Sect. 3.11.3), the ex ante constraints are the perceived RRR constraint (Eqn.19) and the perceived CAR constraint (Eqn.16), which strongly influence the lending behavior of the bank. These behavioral constraints are more restrictive than the actual, ex post constraints, as will be shown below. We interpret this as if our banks are behaving cautiously.

For the RRR constraint this is so, because the excess reserves of the bank are not decreased by the full amount of the granted loan (as specified in the ex ante behavioral constraint in Eqn.19).

When a bank grants a loan, it does not pay out of its cash fault, nor does it pay the loan out of its reserves. Hence, the mere creation of a loan does not affect the bank's actual reserves immediately, at least not initially. What the bank does is it creates the loan on the assets side of its balance sheet, and simultaneously creates a temporary account on its liabilities side, thereby increasing the size of its balance sheet. Whether or not this will affect the reserves depends on whether the firm has a payment account with the loan issuing bank, or whether it transfers the money to some other account with a counter-party bank.

In the first case, the money in the temporary account is booked to the firm's demand deposit account with the same bank (see Table 5). This is purely a transformation on the liability side of the loan initiating bank, not affecting its actual reserves in any way. It does however affect the excess reserves by a small amount, since the bank has to cover the new deposits. Suppose the reserve requirement were 1 percent, then a new loan of 100 will require 1 unit of reserves. The new loan of 100 does not change the actual reserves of the bank, since the bank simply increases the size of its balance sheet on both sides. However, the bank needs to take into account that loans create deposits, hence it should cover this with reserves by the fraction given by the reserve requirement. If this were 1 percent, then a new loan of 100 will require 1 unit in reserves, so the excess reserves will decrease by 1 , not by 100 .

Hence, in this case, Eqn. (19) is not model consistent, since it assumes that the bank anticipates a RRR constraint where the excess reserves will decrease by the full amount of 100, while it actually only decreases by 1 . So the bank is acting very cautiously when it assumes the full amount must be taken into account, and therefore restricts its lending too much.

In the second case, the money in the temporary account gets transferred to the counter-party bank (see Table 6). This implies a transformation on both the asset and liability sides of the balance sheets of both banks. The initiating bank reduces its liability side by removing the tempory account balance, and reduces its assets side by transferring reserves to the counterparty bank. The counter-party bank increases its liability side by crediting the firm's demand 
deposit account, and it increases its assets side by receiving the reserves that were transmitted by the loan-initiating bank.

In this second case, the initiating bank reduces its reserves by the exact amount of the loan, and the counter-party bank increases its reserves to the total amount of the loan. If we now consider the effect this has on the excess reserves, then the loan issuing bank was correct in anticipating that the creation of the new loan would reduce its excess reserves by the full amount. Hence eqn. (19) is model consistent.

For the counter-party bank, its actual reserves have increased by the full amount of the loan, hence this also increases its excess reserves. But this bank now has to cover the additional deposits by additional reserves of 1 , so its excess reserves have not actually increased by the full amount of the loan (100), but only by 99 units.

Summarizing, in case one, the loan-issuing bank does not change its actual reserves, but the excess reserves decrease by 1 unit, to cover the new deposits. Hence the behavioral assumption is not model consistent. In case two, the loan-issuing bank reduces its actual reserves by 100 , and excess reserves also decrease by 100 . Hence the behavioral assumption is model consistent. The deposit receiving bank increases its actual reserves by 100, while its excess reserves only increase by 99, since 1 unit of excess reserves must be reserved to cover the new deposits. In total, for the banking sector as a whole, the aggregate actual reserves remain unchanged, and the aggregate excess reserves decrease by 1 . But the distribution of the reserves has changed.

In conclusion, if we consider the reserve requirement as an ex ante behavioral constraint, we are making a conceptual mistake in assuming that the bank anticipates, or believes, that all new loans will be subtracted from its excess reserves to the full amount, while this would only be true if all firms borrow from banks that are different than their own bank. We can re-interpret this assumption by stating that banks always err on the side of caution, and therefore assume the worst case scenario. The bank does not know in advance what the firm will do with the credit it obtains, so the best it can do is to assume that the firm will transfer it to another account.

For the CAR constraint a similar reasoning applies. Here the credit risk that a bank computes is based on the assumption that the loss at default is one hundred percent of the loan, due to the fact that we have assumed that all loans are non-collateralized debt. The assumption of a one hundred percent debt write-off is obviously incorrect, since the model specifies a debt deleveraging of some fraction of the debt. This fraction depends on whether we are dealing with an insolvency bankruptcy (debt write-off is based on total assets, in order to get positive equity) or with an illiquidity bankruptcy (debt write-off is based on total debt in order to improve the debt-to-equity ratio).

The actual loss at default is therefore less than the bank anticipates, so we are always overestimating the credit risk when applying the CAR constraint as specified in Eqn. (16). To be model consistent, that is, to make the anticipated ex ante constraint equivalent to the actual ex post constraint, we should adjust this equation to the actual debt write-off that would occur in case of a failure. However, at the moment the bank has to make a decision whether or not to grant the loan this information is not yet available, hence the bank cannot possibly take this information into account in the ex ante CAR constraint. Also for the CAR constraint we can re-interpret this assumption as stating that banks are erring on the side of caution when they estimate the loss at default. 
Table 5: Loans created when the originating bank (Business Bank B) and the deposit bank (D) are the same entity.

\begin{tabular}{|l|ll|}
\hline Business Bank (B) $=$ Deposit Bank (D) & \\
\hline Assets & Liabilities & \\
\hline CB reserves & Deposits & \\
Loans to firms +100 & $\begin{array}{l}\text { Temp. account } \\
\text { Net Worth }\end{array}$ & +100 \\
\hline CB reserves & Deposits & +100 \\
Loans to firms +100 & Net Worth & \\
\hline \hline (Excess reserves) $\quad-1$ & \\
\hline
\end{tabular}

Table 6: Loans created in an overdraft system: clearing by the central bank through the reserve system.

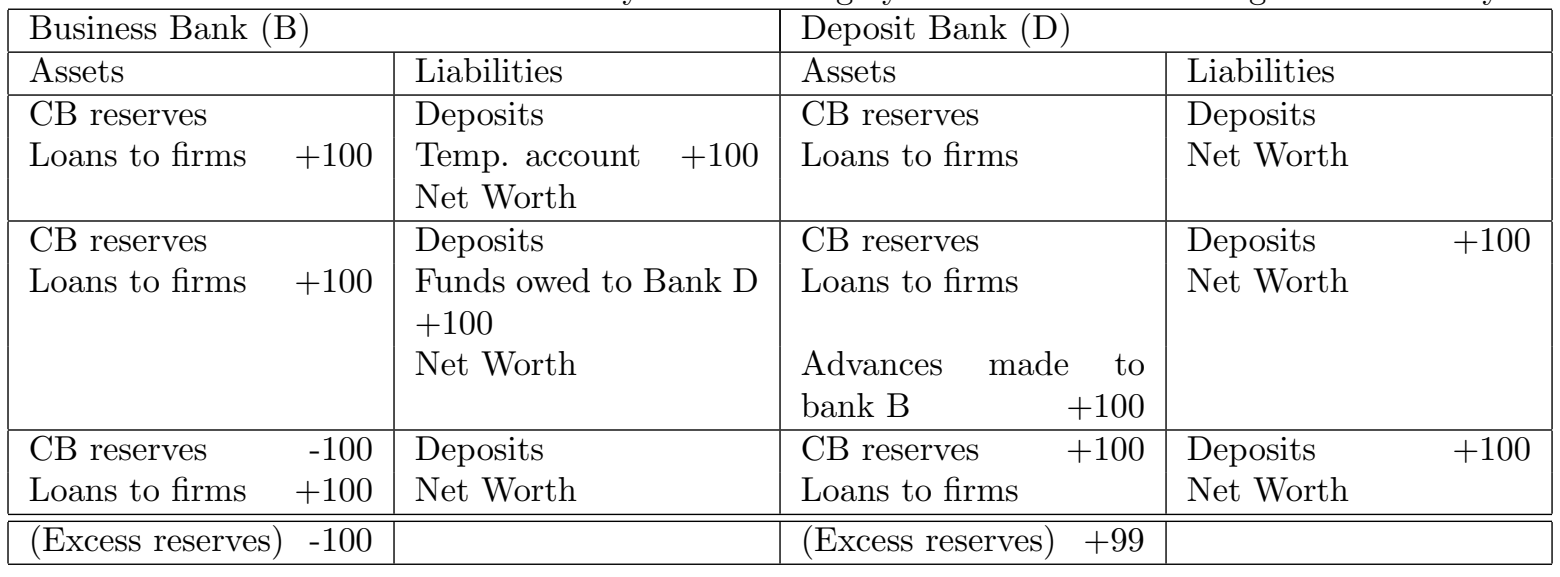




\section{B Appendix: Recession Analysis}

The analysis in Section 4 shows boxplots for the amplitude of recessions. In order to detect such amplitudes, a recession has to be a well-defined statistical object, and an algorithm is needed to detect when a recession starts and when it ends. The algorithm that was used to obtain the results for this paper is based on well-established methods from the empirical literature, such as in Claessens et al. (2011). For business cycles we use the terms expansion (recession) to indicate an increase (decrease) in output, measured by sales in units (real GDP). For financial cycles the corresponding terms are upturn (downturn) for an increase (decrease) in total private sector debt, measured in terms of total firm credit.

\section{B.1 Terminology and Definitions}

The meaning of the statistics are the same as in Claessens et al. (2011).

- All statistics correspond to batch means.

- The determination of peaks and throughs is based on output.

- Duration of a recession is the number of quarters between peak and through.

- Duration for recoveries is the time it takes to attain the level of the previous peak (in quarters).

- The statistics "amplitude" and "slope" are based on sales (in units).

- The amplitude for a recession is the decline in sales during the peak to through decline.

- The amplitude of recoveries is the change in sales from the through level to the level reached in the first four quarters of an expansion.

- Cumulative loss is the combination of duration and amplitude and measures the cost of recessions as the foregone output that was not produced (it is calculated as an integral above the output curve).

- The slope of recession is the amplitude divided by duration. The slope of a recovery is the amplitude from the through to the period when sales reach the level of the last peak, divided by duration.

The following definitions are taken from Claessens et al. (2011, p.10-12):

Peaks and troughs A peak in a timeseries $y_{t}$ occurs at time $t$ if there are 2 periods of increase before, and 2 periods of increase after $\mathrm{t}$ :

$$
(y[t]-y[t-2]>0, y[t]-y[t-1]>0) \text { and }(y[t+2]-y[t]<0, y[t+1]-y[t]<0)
$$

A trough in a timeseries $y_{t}$ occurs at time $\mathrm{t}$ if:

$$
(y[t]-y[t-2]<0, y[t]-y[t-1]<0) \text { and }(y[t+2]-y[t]>0, y[t+1]-y[t]>0))
$$

Recession A recession/downturn is the period between a peak a trough.

Expansion An expansion/upturn is the period between a trough and a peak. 
Recovery A recovery is the early part of the expansion phase, defined as the time it takes for output to rebound from the trough to the peak level before the recession.

Duration of recession The duration of a recession/downturn is the number of quarters, $\mathrm{k}$, between a peak $\left(y_{0}\right)$ and the next trough $\left(y_{k}\right)$ of a variable.

Duration of recovery The duration of a recovery/upturn is the number of quarters $(r)$ it takes for a variable to reach its previous peak level after the trough: $\left\{r>k: y_{r} \geq y_{0}\right\}$.

Amplitude for recession The amplitude of a recession/downturn $A_{c}$, measures the change in $y_{t}$ from a peak $\left(y_{0}\right)$ to the next trough $\left(y_{k}\right): A_{c}=y_{k}-y_{0}$

Amplitude for recovery The amplitude of a recovery/upturn, $A_{u}$, measures the change in yt from a trough to the level reached in the first four quarters of an expansion $\left(y_{k+4}\right): A_{u}=y_{k+4} y_{k}$.

Slope for recession The slope of a recession/downturn is the ratio of the amplitude to the duration of the recession/downturn: $S_{c}=A_{c} / D_{c}$.

Slope for recovery The slope of a recovery/upturn is the ratio of the change of a variable from the trough to the quarter at which it attains its last peak divided by the duration: $S_{r}=$ $\left(y_{r}-y_{0}\right) / D_{u}$.

Cumulative loss for recession The cumulative loss for a recession with duration $k$ combines the duration and amplitude as a measure for the overall costs of recession: $F^{c}=\sum_{j=1}^{k}\left(y_{j}-\right.$ $\left.y_{0}\right)-A^{c} / 2$, where $y_{0}$ is the level of output at the start of the recession, and $y_{j}$ are the successive terms during the recession.

\section{B.2 Detecting peaks and troughs}

Fig.11 shows the detection of peaks and troughs in the time series of output for the business cycle (Panel a) and for the time series of total debt for the financial cycle (Panel c). Fig.11 (Panel b) shows expansions and recessions from peak to trough for the business cycle. This plot does not coincide exactly with the peaks and troughs detected in Fig.11 (a) due to the fact that sometimes two peaks can follow each other without having a through in the middle. This is because the through does not necessarily signal a recession, since it might be too short. In such cases the event is censored, i.e. removed from the plot. Fig.11 (c-d) provides the same type of analysis for the credit cycle. Here the solid lines coincide with peaks in the credit cycle, i.e. with the start of a downturn. Dotted lines indicate throughs in the credit cycle, i.e. the start of an upturn or recovery.

\section{B.3 Statistical properties of business and financial cycles}

Figure 12 shows statistical properties for the duration of the business cycle, in terms of density plots for the duration of recessions and recoveries. The duration of recessions is bi-modal, with modes at 3 and 6 quarters, resp. The duration of recoveries is also bi-modal, but with modes at 1.5 and 5.5 quarters, resp. Similarly, Figure 13 shows statistical properties for the duration of the financial cycle, using density plots for the duration of upturns and downturns in the total 
(a) Business cycle, peaks and throughs

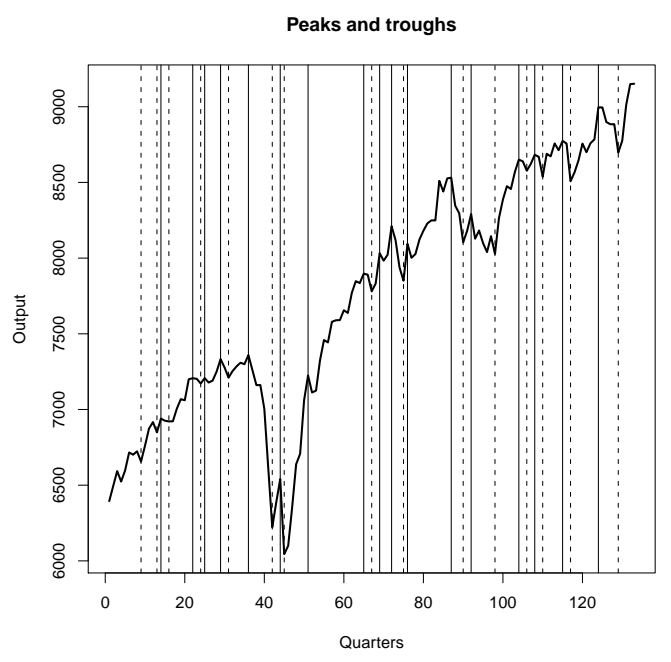

(c) Credit cycle, peaks and throughs

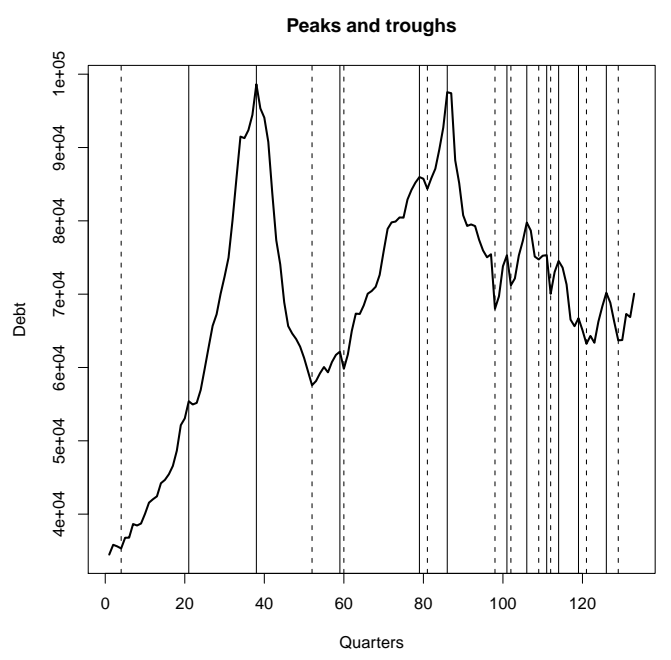

(b) Business cycle, recessions and expansions

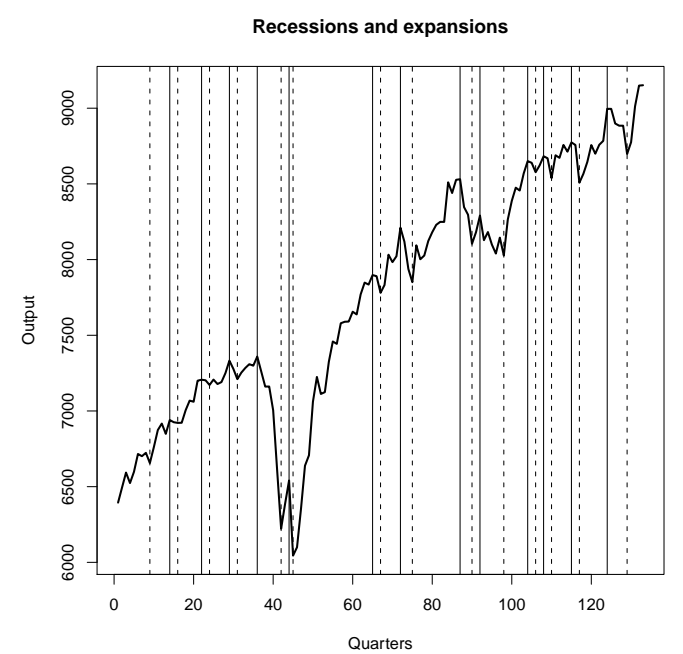

(d) Credit cycle, downturns and recoveries

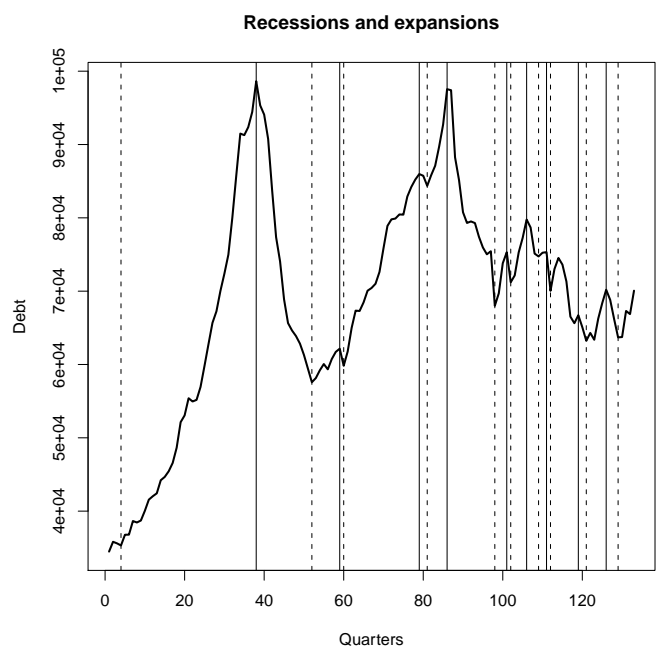

Figure 11: Peaks and troughs for the business cycle and the financial cycle, for 500 months (167 quarters). Solid lines: peaks, or start of a recession; dotted lines: troughs, or start of an expansion. (a-c) Detection of peaks and throughs. (b-d) Recessions and expansions (for the business cycle), and upturns and downturns (for the financial cycle).

debt. The density of the duration of downturns has a mode at 12 quarters, while the density of recoveries shows a mode at 1 quarter. 


\section{Business cycle properties}

(a) Recessions

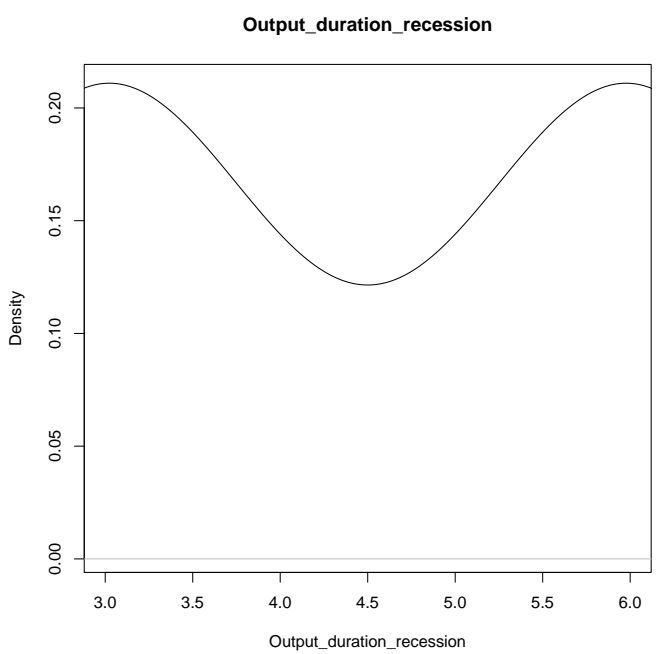

(b) Recoveries

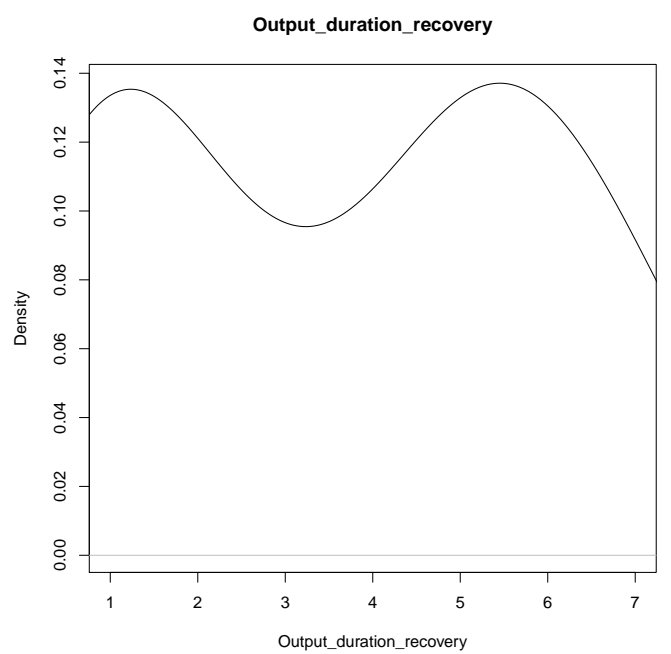

Figure 12: Density plots for the duration of recessions and recoveries along the business cycle.

Financial cycle properties

(a) Downturns

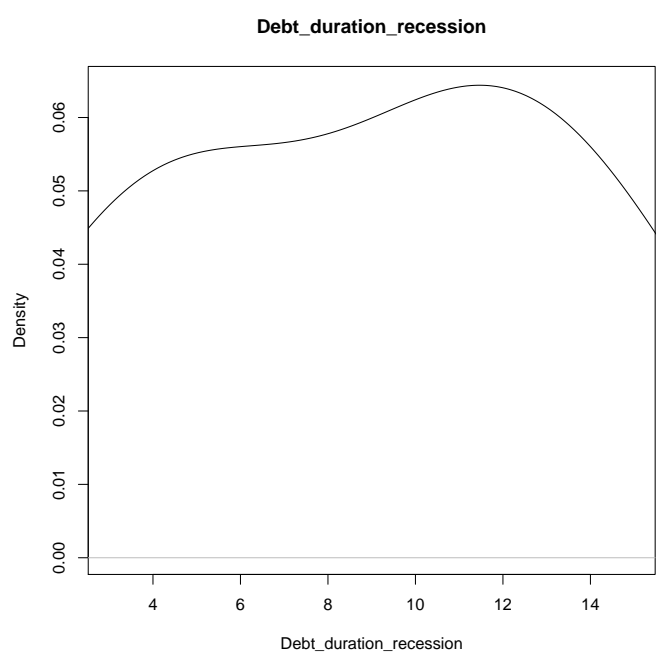

(b) Recoveries

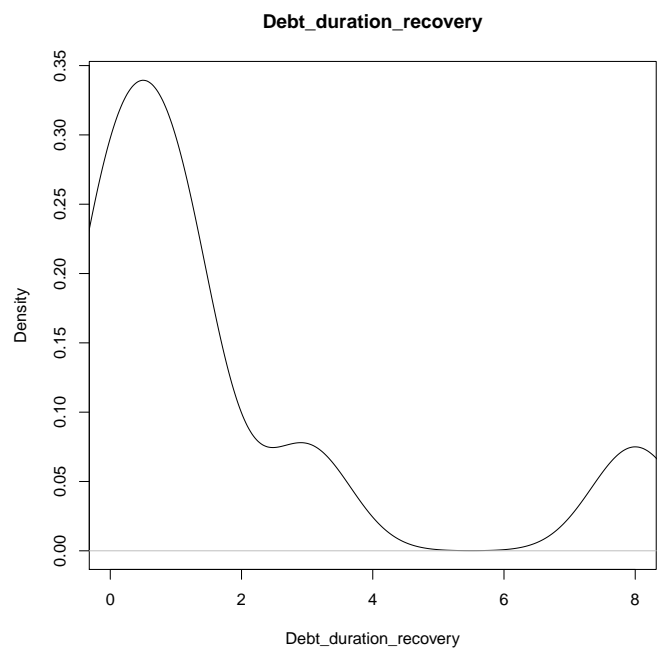

Figure 13: Density plots for the duration of downturns and recoveries along the financial cycle. 


\section{Notes}

${ }^{1}$ Most Central Banks do not vary the reserve requirement ratio all too often. However, the People's Bank of China (PBOC) uses it as a main policy tool for banking regulation.

${ }^{2}$ Speech by Governor Jeremy C. Stein from the FED, held at the Brookings Institution, Washington, D.C. on October 11, 2012: Evaluating Large-Scale Asset Purchases, http://www.federalreserve.gov/newsevents/speech/ stein20121011a.htm, retrieved on Feb. 15, 2015

${ }^{3}$ Alan Greenspan, 11 July 2012, CNBC News Interview, http://www.cnbc.com/id/48155262, retrieved on Feb. 15,2015

${ }^{4}$ Mario Draghi, President of the ECB, Frankfurt am Main, 22 January 2015, Introductory statement to the press conference on the ECB's expanded asset purchase programme. http://www.ecb.europa.eu/press/pressconf/ 2015/html/is150122.en.html, retrieved on Feb. 15, 2015.

${ }^{5}$ EIB website, Investment Plan for Europe, http://www.eib.org/about/invest-eu/index.htm, retrieved on Feb. 15,2015 .

${ }^{6}$ The generic term "investment good" is used to denote machinery and other physical capital goods.

${ }^{7}$ All parameter values are listed in Table 4 . They result from extensive model calibrations to match empirical stylized facts, as documented in Dawid et al. (2012) and Dawid et al. (2015).

${ }^{8}$ The specification of the probability of default depends on the internal risk model of the banks. The Basel II Accord specifies that banks should use an objective ratings-based risk-model, i.e. similar to the models used by ratings agencies, i.e. Moody's, Fitch and Standard \& Poor's. Our specification follows Moody's KMV model, which incorporates the Vasicek-Kealhofer (VK) Model (Vasicek, 1984; Kealhofer, 2003). An important assumption in this model is that there exists only one source of market risk, and this is the only risk factor affecting all firms, for example the aggregate state of the economy. The KMV model is part of the class of structural models, in contrast to the class of reduced models.

${ }^{9}$ A similar specification for the interest rate rule can be found in Delli Gatti et al. (2011, p. 67). The difference with our specification is that we use the probability of default, while they use the leverage ratio.

${ }^{10}$ An alternative behavioural rule for the bank that we have tested is "partial rationing": when the credit risk exceeds the risk exposure budget $V^{b}$, then firm $i$ only receives a proportion of its request, up to the constraint. This rule implies that banks always exhaust their available risk budget and does not result in a viable economy. It leads to more credit rationing rather than less, since firms coming to the bank after a very risky firm has already secured a loan will not be able to receive any loans, because the bank has already exhausted its risk budget.

${ }^{11}$ Note that here we use "partial rationing" for the RRR, while for the CAR we use "full rationing". 


\section{References}

Admati, A., Hellwig, M., 2013. The Bankers' New Clothes: What's Wrong with Banking and What to Do about It. The University Press Group, West Sussex, UK.

Argote, L., Epple, D., 1990. Learning curves in manufacturing. Science 247 (4945), 920-924.

Ashraf, Q., Gershman, B., Howitt, P., 2011. Banks, market organization, and macroeconomic performance: An agent-based computational analysis.

Basel Committee on Banking Supervision, 7 March 2013. Basel III phase-in arrangements. Online: http://www.bis.org/bcbs/basel3/basel3_phase_in_arrangements.pdf, retrieved on 6 January 2015 .

Battiston, S., Delli Gatti, D., Gallegati, M., Greenwald, B., Stiglitz, J. E., 2012. Liaisons dangereuses: Increasing connectivity, risk sharing, and systemic risk. Journal of Economic Dynamics and Control 36 (8), 1121-1141.

Berkmen, P., Gelos, G., Rennhack, R., Walsho, J. P., 2009. The global financial crisis: Explaining cross-country differences in the output impact. IMF Working Paper WP/09/280, International Monetary Fund.

Caballero, R. J., Hoshi, T., Kashyap, A. K., 2008. Zombie Lending and Depressed Restructuring in Japan. American Economic Review 98 (5), 1943-77.

Calomiris, C. W., 28 November 2013. Is a $25 \%$ bank equity requirement really a no-brainer? In: Danielsson, J. (Ed.), Post-Crisis Banking Regulation. Evolution of economic thinking as it happened on Vox. VoxEU.org eBook. Vox.EU, Ch. 2.5, pp. 73-80.

Carroll, C. D., February 1997. Buffer-Stock Saving and the Life Cycle/Permanent Income Hypothesis. The Quarterly Journal of Economics 112 (1), 1-55.

Claessens, S., Kose, A., Terrones, M. E., May 2011. How do business and financial cycles interact? CEPR Discussion Papers 8396, C.E.P.R. Discussion Papers.

Dawid, H., Gemkow, S., Harting, P., van der Hoog, S., Neugart, M., 2011b. Eurace@Unibi Model v1.0 User Manual. Working paper, Bielefeld University .

Dawid, H., Gemkow, S., Harting, P., van der Hoog, S., Neugart, M., 2012. Eurace@Unibi Model: An Agent-based Macroeconomic Model for Economic Policy Analysis. Bielefeld Working Papers in Economics and Managment No. 05-2012 .

Dawid, H., Gemkow, S., Harting, P., van der Hoog, S., Neugart, M., 2015. Agent-based macroeconomic modeling and policy analysis: the Eurace@Unibi model. In: Chen, S.-H., Kaboudan, M. (Eds.), Handbook on Computational Economics and Finance. Oxford University Press.

Dawid, H., Harting, P., Neugart, M., 2014. Economic convergence: policy implications from a heterogeneous agent model. Journal of Economic Dynamics \& Control 44, 54-80.

Delli Gatti, D., Desiderio, S., Gaffeo, E., Cirillo, P., Gallegati, M., 2011. Macroeconomics from the Bottom-Up. Springer.

Delli Gatti, D., Gaffeo, E., Gallegati, M., Giulioni, G., Palestrini, A., 2008. Emergent Macroeconomics: An Agent-Based Approach to Business Fluctuations. Springer. 
Delli Gatti, D., Gallegati, M., 1992. Imperfect information, corporate finance, debt commitments and business fluctuations. In: Fazzari, S., Papadimitriou, D. (Eds.), Financial conditions and Macroeconomic performance: Essays in Honor of Hyman P. Minsky. M.E. Sharpe, New York, Ch. 9, pp. 133-160.

Delli Gatti, D., Gallegati, M., Giulioni, G., Palestrini, A., May 2003. Financial fragility, patterns of firms' entry and exit and aggregate dynamics. Journal of Economic Behavior \& Organization $51(1), 79-97$.

Dosi, G., Fagiolo, G., Napoletano, M., Roventini, A., Treibich, T., 2013. Income distribution, credit and fiscal policies in an agent-based keynesian model. Journal of Economic Dynamics and Control 37, 1598-1625.

Dosi, G., Fagiolo, G., Napoletano, M., Roventini, A., Treibich, T., 2015. Fiscal and monetary policies in complex evolving economies. Journal of Economic Dynamics and Control 52, 166189.

Dosi, G., Fagiolo, G., Roventini, A., September 2010. Schumpeter meeting Keynes: A policyfriendly model of endogenous growth and business cycles. Journal of Economic Dynamics and Control 34 (9), 1748-1767.

Douglas, P. H., Hamilton, E. J., Fisher, I., King, W. I., Graham, F. D., Whittlesey, C. R., July 1939. A program for monetary reform. Unpublished draft manuscript.

Gali, J., Gertler, M., Lopez-Salido, J. D., 2007. Markups, gaps and the welfare costs of business fluctuations. The Review of Economics and Statistics 89 (1), 44-59.

Geanakoplos, J., Jul. 2009. The Leverage Cycle. Cowles Foundation Discussion Papers 1715, Cowles Foundation for Research in Economics, Yale University.

Hanson, S. G., Kashyap, A. K., Stein, J. C., 2011. A macroprudential approach to financial regulation. Journal of Economic Perspectives 25 (1), 3-28.

Jordà, O., Schularick, M., Taylor, A. M., Nov. 2011. When credit bites back: Leverage, business cycles, and crises. NBER Working Papers 17621, National Bureau of Economic Research, Inc.

Kealhofer, S., 2003. Quantifying credit risk i: Default prediction. Financial Analysts Journal 59 (1), 30-44.

Kindleberger, C. P., 2000. Manias, Panics, and Crashes: A History of Financial Crises. John Wiley and Sons, New York, (1st edition 1978).

Koo, R. C., 2009. The Holy Grail of Macroeconomics - Lessons from Japan's Great Recession. John Wiley \& Sons.

Koo, R. C., 2010. A balance sheet recession. INET Online Interview, Retrieved: 23 Oct. 2014.

Krug, S., Lengnick, M., Wohltmann, H.-W., 2014. The impact of Basel III on financial (in)stability: An agent-based credit network approach. Economics Working Papers 2014-13, Christian-Albrechts-University of Kiel, Department of Economics.

Malhotra, N. K., 1984. The use of linear logit models in marketing research. Journal of Marketing Research 21 (1), 20-31. 
Mandel, A., Jaeger, C., Frst, S., Lass, W., Lincke, D., Meissner, F., Pablo-Marti, F., Wolf, S., Sep. 2010. Agent-based dynamics in disaggregated growth models. Documents de travail du Centre d'Economie de la Sorbonne 10077, Universit Panthon-Sorbonne (Paris 1), Centre d'Economie de la Sorbonne.

Minsky, H. P., 1978. The financial instability hypothesis: A restatement. Hyman P. Minsky Archive Paper 180, 541-552.

Minsky, H. P., 1986. Stabilizing an Unstable Economy. Yale University Press, (2nd edition 2008, McGraw-Hill:New York).

Ratnovski, L., 28 July 2013. How much capital should banks have? In: Danielsson, J. (Ed.), PostCrisis Banking Regulation. Evolution of economic thinking as it happened on Vox. VoxEU.org eBook. Vox.EU, Ch. 2.4, pp. 65-72.

Schularick, M., Taylor, A. M., April 2012. Credit booms gone bust: Monetary policy, leverage cycles, and financial crises, 1870-2008. American Economic Review 102 (2), 1029-61.

Stock, J. H., Watson, M. W., 1999. Business cycle fluctuations in us macroeconomic time series. In: Taylor, J. B., Woodford, M. (Eds.), Handbook of Macroeconomics Vol. 1. Elsevier, Ch. 1, pp. $3-64$.

Vasicek, O., 1984. Credit valuation. White Paper, Moodys KMV.

Verho, J., 2008. Scars of recession: the long-term costs of the finnish economic crisis. Working Papers 2008/09, IFAU - Institute for Labour Market Policy Evaluation. 